\title{
Relative Risk of Fatal Crash Involvement by BAC, Age, and Gender
}




\section{Technical Report Documentation Page}

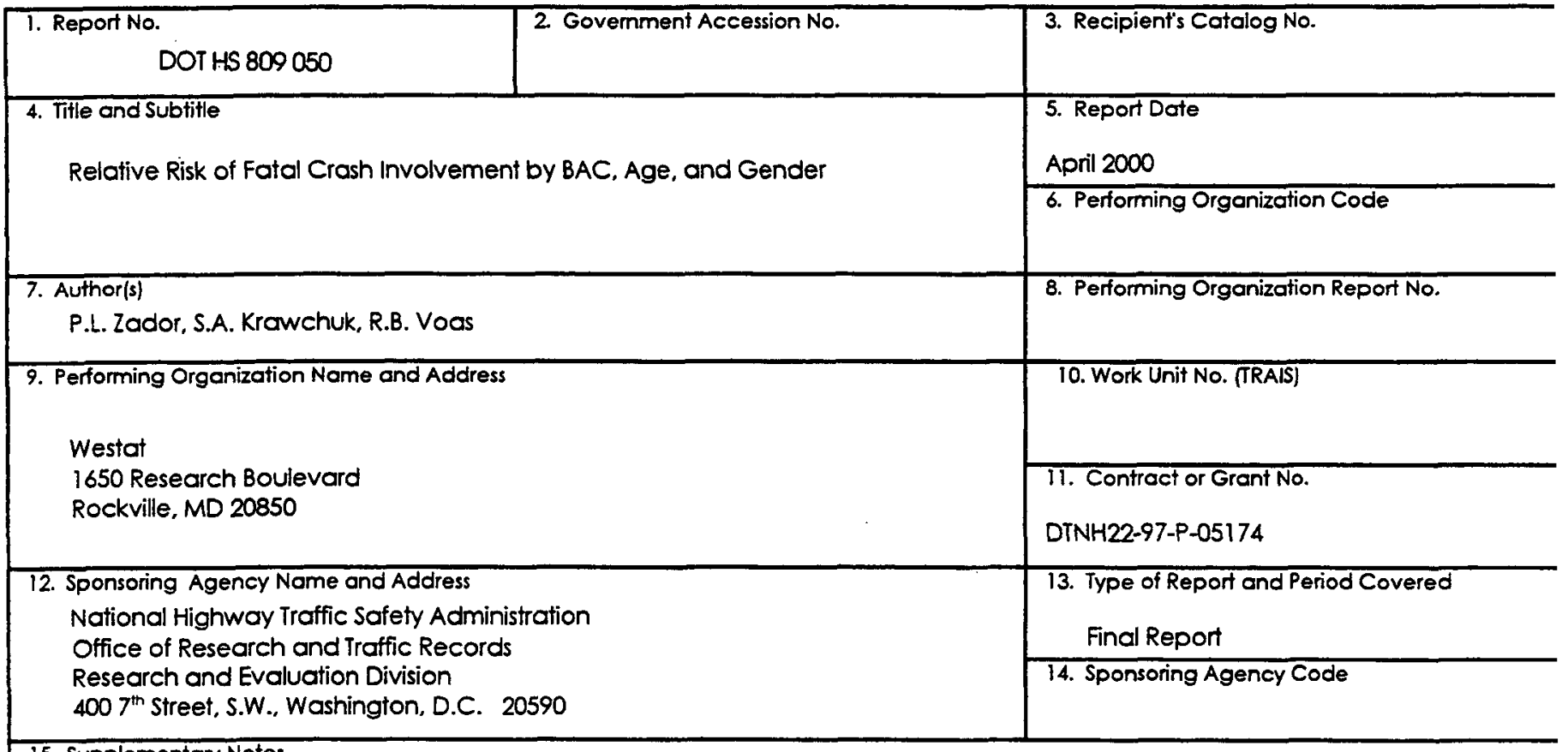

15. Supplementary Notes

Paul J. Tremont, Ph.D was the COTR for this project.

\section{Abstract}

Objective:To re-examine and refine estimates for alcohol-related relative risk of driver involvement in fatal crashes by age and gender as a function of BAC using recent data.

Methods: Logistic regression was used to estimate age/sex specific relative risk of fatal crash involvement as a function of the BAC of fatally injured and surviving drivers by combining crash data from the Fatality Analysis Reporting System with exposure data from the 1996 National Roadside Survey of Drivers.

Results: In general, the relative risk of involvement in a fatal passenger vehicle crash increased steadily with increasing driver BAC in every age/sex group among both fatally injured and surviving drivers. A .02 percentage point BAC increase among 16-20 year old male drivers was estimated to more than double the relative risk of fatal single vehicle crash injury. At the midpoint of the .08-.10 BAC range, the relative risk of a fatal single-vehicle crash injury varied between 11.4 (drivers 35 and older) and 51.9 (male drivers, 16-20). With few exceptions, older drivers had lower risk of being fatally injured in a single vehicle crash than younger driversand females were of lower risk than comparable males.

Conc/usions: This is the first study that systematically estimated relative risk for drinking drivers with BACs between $.08 \%$ and $.10 \%$ (these relative risk estimates apply to BAC range mid-points at $.09 \%$ ). The results clearly show that drivers at non-zero BACs somewhat below .10\% pose substantially elevated risk both to themselves and to other road users.

\section{Key Words}

relative risk, motor vehicle crash, motor vehicle fatality, Blood Alcohol Content (BAC), drinking and driving. FARS, national roadside survey, logistic regression, multiple imputation

19. Security Classif. (of this report)

Unclassified
18. Distribution Statement

This report is available from the National Technical Information Service (NTIS), Springfield, Virginia 22161, tel. 703.605.6000, and from the NHTSA web site at www.nhtsa.dot.gov.

21. No. of Poges




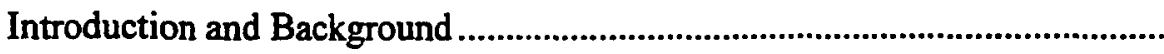
Methods.

\section{List of Appendices}

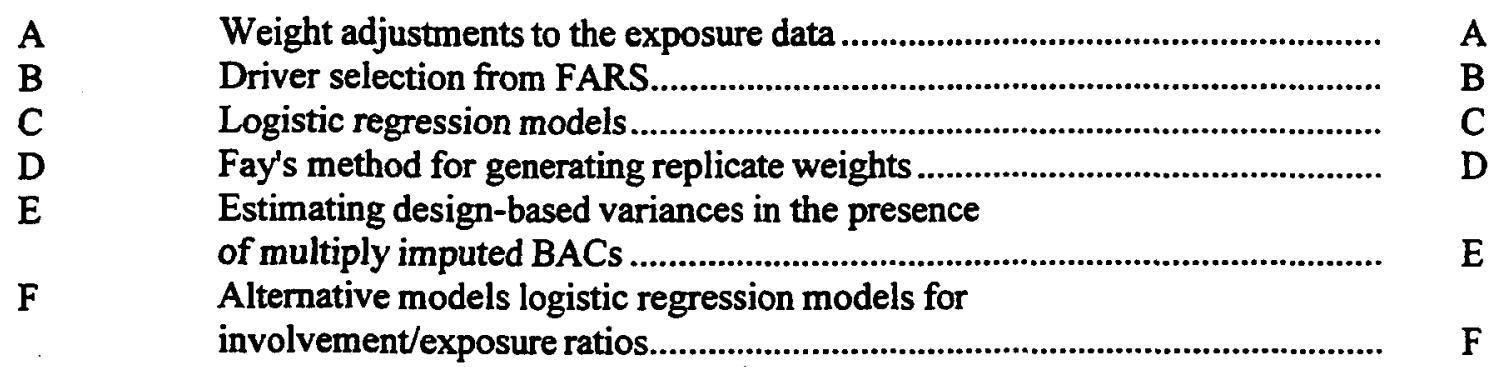


Table of Contents (continued)

\section{List of Figures}

Figure

$\underline{\text { Page }}$

$1 \quad$ Relative fatality risk for drinking drivers

by age and sex in single vehicle crashes

8

Relative risk for the involvement of drinking drivers

by age and sex in all passenger vehicle crashes

Baseline risk at $\mathrm{BAC}=0$ relative to male $21-34$ group

\section{List of Tables}

Table

Page

1.1 Exposure survey sample size $(\mathrm{N})$ and weighted percent distribution (\%) by sex, age, and BAC in the 48 contiguous states during weekend nights.

Data from $96 \mathrm{NRS}$

1.2 Frequency $(\mathrm{N})$ and percent distribution (\%) of driver fatalities in single vehicle crashes by sex, age, and BAC in the 48 contiguous states during weekend nights.

Data from FARS, years 95-96.

Relative risk and relative risk confidence bound estimates for fatalities and fatal crash involvement at zero driver BAC by the number of crash-involved vehicles, sex, and age, using male drivers aged 21-34 as the baseline.

Data from the 90NRS and FARS, years 95-96.

Regression diagnostics for logistic regression models for fatality risk and fatal crash involvement risk by the number of crash-involved vehicles. Data from the 96NRS and FARS, years 95-96.

The effect of BAC, sex, and age on fatality risk and fatal crash involvement risk estimates based on logistic regression models by the number of crash-involved vehicles.

Data from the 96NS and FARS, years 95-96.

Model-based estimate for factor of proportionate increase (FPI) in relative fatality risk and relative involvement risk associated with a $0.02 \%$ increase in BAC by the number of crash-involved vehicles, sex, and age.

Data from the 9NRS and FARS, years 95-96.............................................. 


\section{Table of Contents (continued)}

\section{List of Tables (continued)}

Table

6.1 Model-based relative driver facility risk and risk confidence bound estimates for single vehicle crashes by $\mathrm{BAC}$, sex, and age, using zero $\mathrm{BAC}$ as the baseline.

Data from the $9 \mathrm{NRS}$ and FARS, years $95-96$

6.2 Model-based relative driver involvement risk and risk confidence bound estimates for single vehicle crashes by BAC, sex, and age, using zero BAC as the baseline.

Data from the 9@NS and FARS, years 95-96

6.3 Model-based relative driver fatality risk and risk confidence bound estimates for two vehicle crashes by BAC, sex, and age, using zero BAC as the baseline.

Data from the 9๑RS and FARS, years 95-96.

6.4 Model-based relative driver involvement risk and risk confidence bound estimates for two vehicle crashes by BAC, sex, and age, using zero $\mathrm{BAC}$ as the baseline.

Data from the 96NS and FARS, years $95-96$

6.5 Model-based relative driver fatality risk and risk confidence bound estimates for all passenger vehicle crashes by $\mathrm{BAC}$, sex, and age, using zero $\mathrm{BAC}$ as the baseline.

Data from the 96NRS and FARS, years 95-96.

6.6 Model-based relative driver involvement risk and risk confidence estimates for all passenger vehicle crashes by BAC, sex, and age, using zero $\mathrm{BAC}$ as the baseline.

Data from the 90NR and FARS, years 95-96. 


\section{Introduction and Background}

According to National Highway Traffic Safety Administration (NHTSA) information, as of the end of September 1999, 31 states defined driving with a blood alcohol concentration (BAC) above $0.10 \%$ as a crime per se, while another 17 states plus the District of Columbia set their per se limit at $0.08 \%$. Due to a combination of legal measures, enforcement actions, and changes in voluntary behavior patterns, alcohol-related fatalities have been declining for nearly two decades, both in absolute numbers and as a proportion of all fatalities. Nonetheless, there were still 15,936 alcohol-related traffic fatalities in the United States which accounted for nearly $38 \%$ of total traffic fatalities in 1998 (U.S. DOT, 1999) indicating that much more needs to be done.

Based on extensive research over several decades, we now have overwhelming evidence showing that even BACs as low as $0.02 \%$ impair driving-related skills. One line of such evidence grows out of laboratory research with dosed subjects (Moskowitz and Robinson, 1987; see also U.S. Department of Health and Human Services (HHS), 1997, Chapter 7). Confirming evidence comes from field research that compares the BACs of crash-involved with non-crash-involved drivers to determine the relative risk of crash involvement (Zador, 1991; see also Perrine et al., 1989, for a review). Two types of relative risk studies have been conducted. "Classical" studies such as that of Borkenstein et al. (1974) used a procedure in which data from non-crash-involved drivers were collected at the same times and locations as the reference crash had occurred. This procedure was adopted in an effort to ensure that the only potential difference between the crash and non-crash driver would be the presence or absence of alcohol. An alternative survey procedure was employed by Zador (1991). He compared crash-involved drivers from the National Highway Traffic Administration, Fatality Analysis Reporting System (FARS), with data from the 1986 National Roadside Survey (NRS) (Wolfe, 1986). This procedure loses some of the precision provided by using the site of the reference crash as the basis for selecting comparison cases. However, it gains reliability because it uses larger numbers and a broader representation that relates to the country as a whole, rather than to a single locality.

The selection of cases that define the crash-involved and non-crash-involved drivers bears significantly on the resulting risk curves. Clearly, many drivers are involved in crashes through no fault of their own but because of the mistakes of others. Therefore, it is important to consider responsibility in selecting the crash-involved drivers. This is generally accomplished by including only drivers in single vehicle crashes (i.e., other drivers were not involved). Previous relative risk studies have demonstrated that the relationship between BAC and crash risk is much stronger for drivers in single vehicle crashes than for drivers in multiple vehicle crashes (Perrine et al., 1989; Zador, 1991). Three methods of selecting comparison cases have been used in previous studies. As noted above, comparison drivers have been interviewed at crash sites (Borkenstein et al., 1974), through national roadside surveys (Zador, 1991; for overview, see also Chapter 10 in HHS, 1993) and through the selection of nonresponsible drivers in multiple vehicle crashes - so called "induced exposure" (Hurst, 1974; Borkenstein et al., 1974). Hurst's analysis of nonresponsible drivers indicated that their crash risk curve was flat and did not increase with higher BACs.

The objective of the present research is to re-examine and refine relative fatal crash risk estimates in a systematic fashion using more recent data. The study was based on U.S. data on drivers in fatal crashes during 1995 and 1996 obtained from the Fatality Analysis Reporting System (NHTSA, FARS), and driver exposure data obtained from the 1996 National Roadside Survey (Voas et al., 1997). It extends similar prior work by the first author in three important ways. Firstly, we estimate relative risk for the policy-relevant $\mathrm{BAC}$ range between $0.08 \%$ and $0.10 \%$. Secondly, we estimate relative risk for six driver

\footnotetext{
'A per se law defines it as a crime to drive with a BAC at or above the proscribed level.
} 
groups: (1) Driver fatalities in single vehicle crashes, (2) Driver involvements in single vehicle fatal crashes, (3) Driver fatalities in two vehicle crashes, (4) Driver involvements in two vehicle fatal crashes, (5) Driver fatalities in all crashes, and (6) Driver involvement in all fatal crashes. Thirdly, we employ statistical methods to estimate both the effect of sampling roadside exposure, and the effect of multiple imputation of missing BACs on the uncertainty of relative risk estimates.

\section{Methods}

\section{Data Sources}

\section{Driver Exposure Data: the 1996 Roadside Survey}

Following the same principles as its two predecessors in 1973 and 1986, the 1996 National Roadside Survey (90NRS) of weekend, nighttime drivers in the 48 contiguous states, interviewed as: breath-tested a sample of noncommercial operators of four-wheel vehicles during a roughly one montr period in the Fall of 1996. Counties with a population of less than 20,000 were not sampled, and in counties with larger populations, roadways with average daily traffic below 2,000 were excluded from the surveys (for details, see Lestina et al., 1999). Drivers were selected for interviews and breath tests using a geographically stratified multi-stage cluster sample. This survey was designed based on the National Automotive Sampling System/Crashworthiness Data System (NASS/CDS, 1995). The first stage of the design comprised 24 Primary Sampling Units (PSUs) employed by NASS/CDS, six each in the Northeast, South, West, and Midwest. Only the section of the NASS PSUs appropriate for the 48 states were employed in the 1996 sampling plan. The second stage comprised a total of 46 police jurisdictions, 11-12 per region. At the third stage, square grids with sides roughly equal to one mile were superimposed on the sampled jurisdictions, and then randomly sampled to obtain the requisite number of squares (this procedure was modified for areas with low road density). Once a square was chosen, the survey was conducted at the first safe area found in it by the survey team leader. Driver selection represented the final stage: the first driver who approached the site after an interviewer became available was stopped for the next interview. Field operations were conducted on Friday and Saturday nights during two two-hour periods at separate sites, at one site between $10 \mathrm{PM}$ and midnight, and at the other between $1 \mathrm{AM}$ and 3 AM. Data from the 96 NRS is representative only of locations and periods when drinking and driving is most prevalent (i.e., not all times or roadways in the 48 contiguous states).

Data from 9NRS were used to estimate the approximate distribution of driver exposure by sex, age $(16-20,21-34$, and $>35)$, and BAC $(0.000,0.001-0.019,0.020-0.049,0.050-0.079,0.080-0.099$, $0.100-0.149$, and $0.150+$ ). Specifically, we approximated the statistical distribution of drivers on weekend nights using the distribution of driver sampling weights after adjustments for nonrespondents (see Appendix A).

\section{Data on Drivers in Fatal Crashes}

The Fatality Analysis Reporting System (FARS) is a census of all motor vehicle crashes that occur on a public trafficway in the United States and result in a fatality within 30 days. Although FARS is maintained by NHTSA of the U.S. Department of Transportation, the data in FARS are obtained through cooperative agreements with agencies in each state's government, and are managed by Regional Contracting Officer's Technical Representatives located in the ten NHTSA Regional Offices. For basic data elements associated with a fatal motor vehicle crash, reporting is usually of very high quality with relatively few missing values with one exception: even in recent years, BACs were not available for many drivers involved in fatal crashes. To deal with this problem, NHTSA has employed a statistical method for imputing missing BACs since the early 1980s, (Klein, 1986). More recently, the method of multiple 
imputation (Rubin, 1987) was adopted to handle the problem of missing BACs on FARS (Rubin et al., 1999). Under multiple imputation, each missing value is replaced by a small number of imputed values (10, in the present case) which are generated by a statistical procedure designed to reflect the statistical properties of the missing driver BACs. We used the ten complete-data versions of FARS in our statistical analyses. Note that while the data files for the multiple imputation method are available, NHTSA is not yet using the multiple imputation method for its published alcohol estimates. The same method used in previous years is to be used for the 1998 FARS estimates.

We classified drivers of four-wheel passenger vehicles involved in fatal crashes during 1995 or 1996 by the number of crash-involved vehicles (one, two, and any number (one, two, or more) of vehicles) and by whether or not the driver was just involved in the crash, or was also fatally injured in the crash. We thus defined six driver groups for analysis: drivers fatally injured in single vehicle crashes, drivers involved in fatal single vehicle crashes, drivers fatally injured in two vehicle crashes, drivers involved in fatal two vehicle crashes, drivers fatally injured in a crash, and drivers involved in a fatal crash. We then screened drivers using criteria that approximately matched the criteria for selecting the exposure sample. We included drivers of passenger vehicles involved in crashes during weekend nights and excluded crashes that occurred on interstates, other urban freeways, and expressways (for additional details, see Appendix B). There were only two notable differences between the exposure and the crash screening criteria, and both were disregarded to increase the sample size for drivers retained for the analyses. First, we accepted crashes that occurred between midnight and $1 \mathrm{AM}$, since those crashes were excluded from the exposure sample only to permit the survey team to change location, and not because BAC distribution between midnight and $1 \mathrm{AM}$ was thought to be different. Second, we did not restrict crashes to the weekend nights during which the surveys were conducted. Including weekend nights for the whole year increased sample sizes almost 12-fold, and introduced no substantial difference in the distribution of driver BACs since driver BACs varied little between the survey period and the rest of the year.

We classified the six groups of driver fatalities and involvements in the same way as we classified the exposure sample, by sex, age $(16-20,21-34$, and $>35)$, and BAC $(0.000,0.001-0.019,0.020-0.049$, $0.050-0.079,0.080-0.099,0.100-0.149$, and $0.150+$ ).

\section{Statistical Methods}

\section{Using Odds Ratios and Logistic Regression to Estimate Relative Risk}

Following Zador (1991), we base our methods on the intuitive notion that comparisons between the frequency distribution of fatal crash involvement by sex, age and BAC and the frequency distribution of roadside exposure by sex, age, and BAC can provide a good yardstick for measuring the effect of these factors on the relative likelihood of fatal crash involvement per unit of driving exposure. Since the 96NRS did not provide a national estimate for total miles driven on weekend nights, it was not possible to scale fatal involvement and exposure count ratios to the corresponding involvement rates per miles driven. However, since our involvement (or fatality) count per exposure ratios are proportional to national involvement (or fatality) rates, dividing two such ratios, say at different BACs, gives the corresponding ratio of involvement (or fatality) rates. Thus, data on fatal involvement from FARS and driving exposure from 96NRS can be used to estimate involvement per exposure ratios which, in turn, effectively approximate relative crash risk. ${ }^{2}$

\footnotetext{
${ }^{2}$ For a general discussion of relative risk, see Schlessellman, J.J. Case-Control Studies: Design, Conduct and Analysis. New York: Oxford University Press, 1982.
} 
More specifically, consider a two way table formed of fatality and (weighted) survey counts for two populations (group 1 and group 2):

\begin{tabular}{lcc}
\hline Population & Fatality Count & Exposure Count \\
\hline Group 1 & F1 & E1 \\
Group 2 & F2 & E2 \\
\hline
\end{tabular}

The odds ratio:

$$
\text { Odds Ratio }=(\mathrm{F} 1 / \mathrm{E} 1) /(\mathrm{F} 2 / \mathrm{E} 2)
$$

compares the fatality/exposure ratio between groups 1 and 2. Taking group 2 as the baseline, this odds ratio compares fatality odds in group 1 to fatality odds in group 2. Odds ratios (OR) being scale invariant, we can substitute $\mathrm{cE} 1$ and $\mathrm{cE} 2$ in (1) for exposure counts $\mathrm{E} 1$ and E2, where $\mathrm{c}$ is the scaling constant, without affecting the numeric value of the OR. Now, for a large value of $c$, the odds in the numerator and the denominator of (1) have approximately the same value as the corresponding crash rates: $F 1 /(F 1+c E 1)$ and $F 2 /(F 2+c E 2)$. The unknown value of $c$ that would scale up survey-based exposure counts to the national total of miles driven is extremely large relative to observed involvement/exposure ratios. Therefore, it is legitimate to use the odds ratios (F1/E1)/(F2/E2) to estimate relative risk, $\mathrm{F} 1 /(\mathrm{F} 1+\mathrm{cE} 1) / \mathrm{F} 2 /(\mathrm{F} 2+\mathrm{cE} 2)$. Given this discussion, and following the common practice in epidemiology, ${ }^{3}$ we used odds ratios to estimate relative risk, and henceforth we will refer to estimates of relative risk, rather than to estimates of odds ratios.

We used logistic regression ${ }^{4}$ to model involvement (or fatality) counts relative to exposure counts, and performed two sets of analyses for each of our six driver sets. In the first set (results are found in Table 2), we estimated relative risk among drivers with zero BAC by age and gender. In these models, we chose male drivers between ages 21 and 34 for baseline, and estimated relative involvement risk for the other five driver groups. In the second set (results in Table 6.1 - 6.6), we estimated relative risk as a function of driver $\mathrm{BAC}$ within sex and age groups. In the latter models, drivers with $\mathrm{BAC}=0$ were chosen as baseline. Note that any non-significant interaction terms were not retained in the final model. For both analyses, in addition to relative risk, we also estimated lower and upper confidence bounds for relative risk.

We estimated relative risk by exponentiating model parameter estimates for the effect of BAC for driver groups of interest. The formula for relative risk $(R R)$ associated with a BAC value was, $R R(B A C)=\exp (b B A C)$, where $b$ denotes the regression coefficient estimate for a BAC variable. Similar other formulae are given in Appendix $\mathrm{C}$ for estimating lower/upper bounds for relative risk.

\section{Model Performance}

We assessed model performance using four statistics: 1) the heterogeneity factor estimated as the Pearson chi-square statistic divided by its degrees of freedom, 2) the maximum of rescaled $\mathrm{R}^{2}, 3$ ) the Hosmer-Lemeshow goodness-of-fit test p-value, and 4) the Wilk-Shapiro statistic p-value for testing the

\footnotetext{
${ }^{3}$ For a general discussion of relative risk, see Schlessellman, J.J. Case-Control Studies: Design, Conduct and Analysis. New York: Oxford University Press, 1982.

4 Logistic regression was implemented using the SAS procedure, Proc Logistic (SAS Institute, Inc. 1996).
} 
normality of standardized Pearson residuals. For data that are conditionally binomial, the dispersion parameter is approximately equal to 1 . A heterogeneity factor substantially larger than one is indicative of overdispersion - that is, more variation than would be expected under the assumption that conditionally on the sum of exposure and fatality counts, the fatalities were binomially distributed. We adjusted all variance and confidence bounds for the presence of overdispersion. The maximum rescaled $\mathrm{R}^{2}$ (Nagelkerke, 1991) can be used to assess model quality somewhat in the manner of the customary $\mathrm{R}^{2}$ statistic for linear regressions. The Hosmer-Lemeshow test statistic is a direct measure for a logistic regression model's ability to predict outcome probabilities (Hosmer and Lemeshow, 1989). We have applied the Wilk-Shapiro test to determine whether standardized residuals followed an approximate normal distribution. In the ideal case, heterogeneity factor and rescaled $R^{2}$ are near one, and the $p$ values are between 0.05 and 0.95 .

\section{Variance Estimation}

As described earlier, the 1996 National Roadside Survey had a complex, multi-stage design. If no special steps were taken, standard statistical packages would tend to underestimate true variability for data collected under a complex design. We used Fay's method of balanced repeated replications (BRR) to obtain design-consistent variance estimates for important model parameters. This involved three steps. First, we used Westat's implementation of Fay's method (WesVarPC, 1998) to create replicate weights from the adjusted full-sample weight (see Appendix D). Second, we repeatedly estimated our models using the full-sample weight, and each set of replicate weights. Finally, we combined the resulting estimates using a simple formula to obtain design-unbiased variance estimates (see Appendix E).

As part of data preparation, NHTSA had replaced missing driver BACs on FARS by ten imputed BAC values (Rubin et al., 1999). On the one hand, having imputed values on FARS made it possible to employ complete-data methods in our analyses. On the other hand, unless special care is exercised, using imputed values as if they were actual values would result in underestimating variability (Rubin, 1987). We followed Rubin's two-step method to eliminate this bias. In Step 1, we re-estimated our models using each of the ten imputed BAC values and averaged the results. In Step 2, we combined the 10 sets of estimates into one single unbiased variance estimate (see Appendix E). Since there were 12 replicate weights for exposure and 10 multiply-imputed completed sets of driver counts, we estimated model parameters for each of the six driver populations a total of 130 times in order to compute imputationadjusted and design-consistent parameter variances

\section{Results}

According to Table 1.1, about $84 \%$ of the weighted drivers in the exposure sample had a zero BAC, about $9.2 \%$ had a non-zero BAC under $0.05 \%, 4.7 \%$ had a BAC between $0.05 \%$ and $0.1 \%, 2.1 \%$ had a BAC between $0.1 \%$ and $0.15 \%$, and only $0.6 \%$ of the weighted roadside sample had a BAC over $0.15 \%$. Overall, males accounted for about $65 \%$ of all exposure. Drivers between 21 and 34 years of age and drivers over 34 years of age were represented roughly in equal proportions among both males and females. Drivers 16-20 accounted for about half the exposure of the other two age groups among females, but less than half among males.

For all six driver involvement groups, driver BAC distributions differed strikingly from the corresponding exposure distribution in every sex-age group, as shown by comparing Table 1.1 to Table 1.2. Even among sober drivers (i.e. $B A C=0$ ), striking differences were found in involvement/exposure ratios across sex and age groups, as indicated in Table 2. Taking the risk of being killed in a single vehicle crash to be 1.00 for sober male drivers $21-34$, the comparable risk was 1.75 for sober male drivers 16-20, and it was 0.71 for sober male drivers over age 34 . In every age group, sober female drivers had a 
lower risk of being killed in a single vehicle crash than sober male drivers, with relative risks decreasing from 1.18, among the youngest group of females, to 0.28 among the oldest group. Note that controlling for sex, confidence intervals for adjacent age groups did not overlap (except for the two highest age group females), and controlling for age groups, the confidence intervals for males and females, did not overlap (except for the youngest age group). Thus, most sex and age group related differences in single vehicle driver fatality rates were not attributable to chance variation. Note that the distributions of fatally injured drivers for each driver involvement group are available from the first author.

Sex and age affected a driver's relative risk of being involved in a fatal single vehicle crash in much the same way as it affected the driver's relative risk of being killed in one. In contrast, Table 2 shows that the pattern of results differed markedly for two vehicle crashes from the pattern of results for single vehicle crashes, especially for females. First, although relative risk still decreased with increasing age among males, the differences were smaller for two vehicle crashes than for single vehicle crashes. Moreover, relative involvement risk was lower for sober 21-34 females than for any of the two other female age groups, but the confidence intervals overlapped for females. Also, the relative fatality risk of sober females 35 and over exceeded the relative fatality risk of sober males 21-34.

Tables 3, 4, 5, and the Table 6 series, present selected model diagnostics, logistic regression model parameter estimates and standard errors, model-based estimates of proportionate increase in relative involvement risk and fatal injury risk associated with a $0.02 \%$ increase in BAC, and model-based relative risk estimates with their confidence intervals, respectively. Models in Table 4 include nine parameters.

1. Indicator variables $(\mathrm{N}=3$ ) for $A G E$ groups: $16-20,21-34$, and $>34$,

2. Indicator variable for being female,

3. Indicator variable for interaction term involving low positive $\mathrm{BAC}(0.001 \%-0.019 \%)$ among drivers $>20$,

4. Continuous variables (interaction terms) $(N=3$ ) for the effect of $B A C$ by age group: 16-20, $21-34$, and $>34$,

5. Continuous variable (interaction term) for the effect of BAC for females 16-20.

As evidenced by the results of the Hosmer-Lemeshow goodness-of-fit test and the Shapiro-Wilk test for the normal distribution of standardized Pearson residuals, relative risk was adequately represented by the models in Table 4 for three of the driver groups: drivers involved in a fatal single vehicle crash, drivers killed in a single vehicle crash, and drivers killed in any crash (see Table 3). These models accounted for substantial percentages of the explainable variation: $68 \%$ among drivers killed in a single vehicle crash, $53 \%$ among drivers killed in any crash, and $49 \%$ among drivers involved in a fatal single vehicle crash. These data also exhibited statistically significant, but relatively modest heterogeneity. While the Hosmer-Lemeshow test statistic $(p=0.032)$ rejected the hypothesis of model fit for fatally injured drivers in two vehicle crashes, the regression model explained $65 \%$ of all explainable relative risk variation, and the standardized Pearson residuals were normally distributed. All-in-all, we deem model fit acceptable for driver fatalities in two vehicle crashes. In contrast, the models performed poorly for the two remaining driver groups - drivers in fatal crashes involving two vehicles or drivers in fatal crashes involving any number of vehicles. Specifically, both Hosmer-Lemeshow test statistics rejected the hypothesis of model fit, both models explained only about $30 \%$ of the explainable relative risk variation, both heterogeneity factors were over 3 , and even the residuals were not normally distributed for drivers in fatal crashes involving any number of vehicles. 
We explored the way our models broke down for fatal two vehicle crashes in considerable detail. We examined model fit statistics for the models in Table 4, and for several other model specifications, ${ }^{5}$ including specifications obtained by stepwise regression. The results clearly showed that sober driver involvement in two vehicle crashes is not closely related to driver involvement at positive BACs, and we discovered that only the inclusion of indicator variables representing overall sober driver risk, and sober driver risk by age and gender, would produce acceptable model fit. This result was, in fact, not too surprising for two reasons. First, in crashes involving more than a single vehicle, some driver(s) may be innocent, and probably sober, victim(s) whose vehicle(s) were struck by a high BAC at-fault driver. Secondly, in multi-vehicle crashes, crash configuration and vehicle occupancy become important determinants of relative risk. However, we decided not to use regression models that included sober driver risk variables (e.g., main effect for zero BAC, zero BAC by age interaction, etc., see Appendix F) because it was not clear how these models can be used to estimate relative risk with $B A C=0$ as the baseline. Therefore, relatively poor model fit notwithstanding, we believe that the relative risk estimates presented from the model parameter estimates in Table 4 provide reasonable, albeit conservative, approximations of the true relative risk even for driver involvement in multi-vehicle fatal crashes. Additional research will be needed to improve model fit for these driver groups.

We computed relative risk as a function of $\mathrm{BAC}$ from one or more regression coefficients relative to sober driver risk, that is relative to the risk of drivers with $0.0 \% \mathrm{BAC}$ (for positive BACs, we re-scaled percent $B A C$ by a factor of a 1000 so that $0.1 \%$ was entered in formulas as 100 ). For example, the relative risk of receiving a fatal injury in a single vehicle crash by a driver $21-34$ whose BAC is $0.13 \%$ was estimated at $R R(0.13)=\exp (0.029 \times 130)=43.4$, where $130=0.13 \times 1000$, and $b=0.029$ is the regression coefficient from Table 4 for the parameter "BAC, Age 21-34". In other words, among drivers $21-34$, a BAC of $0.13 \%$ increased the chance of being killed in a single vehicle crash by a factor of about 43. Table 5 shows model-based estimates for factor of proportionate increase in relative risk associated with an increase of $0.02 \%$ in BAC level for each driver group, by age and sex. Of noteworthy mention, it was estimated that each 0.02 percentage point increase in the BAC of a driver with a non-zero BAC more than doubled the risk of receiving a fatal injury in a single vehicle crash among male drivers $16-20$, and nearly doubled the comparable risk among the other driver groups. Proportionality factors were estimated from age-specific regression coefficients of BAC in Table 4 except that for female drivers 16-20, the estimates were adjusted for the effect of being female. For the relative risk estimates in subsequent tables, relative risk was also adjusted for the effect of low BAC $(0.001 \%-0.019 \%)$ for drivers 21 or older. For the purpose of fitting models, we represented BAC class intervals (by sex and age) by average driver BAC. However, to facilitate comparisons across driver populations, we present relative risk estimates at constant BACs $(0.0 \%, 0.01 \%, 0.035 \%, 0.065 \%, 0.090 \%, 0.125 \%)$ that correspond to class interval midpoints for the first five BAC categories, and $0.220 \%$ for the last BAC category, which corresponds to the average $B A C$ of those with $B A C$ values greater than $0.15 \%$.

The relative risk of receiving a fatal injury in a single vehicle crash increases steadily with increasing driver BAC for both males and females in every age group with one exception (see Figure 1 and Table 6.1). Among all male and female drivers, except those in the 16-20 group, the relative risk of receiving a fatal injury is lower for drivers with a positive BAC under $0.02 \%$ than for drivers with $0.0 \%$ BAC. Remarkably, however, for the 16-20 age group, the comparable relative risk was substantially increased even at this low positive $\mathrm{BAC}$, by $55 \%$ among males, and by $35 \%$ among females. Looking at relative risk across the six age and gender groups, we find that at a BAC of $0.035 \%$, it was elevated by a factor between 2.6 and 4.6 , at a BAC of $0.065 \%$, by a factor between 5.8 and 17.3 , at a BAC of $0.09 \%$, by a factor between 11.4 and 52 , at a BAC of $0.125 \%$, by a factor between 29.3 and 240.9 , and at a BAC of $0.220 \%$, by a factor between 382 and 15,560 . Figure 1 indicates that relative risk increased fastest for

\footnotetext{
${ }^{5}$ Dozens of other models were examined; for a few, results are summarized in Appendix $F$.
} 
males 16-20, and slowest for drivers of either sex 35 and over. In general, controlling for age, relative risk increased faster for males than for females, and controlling for sex, it increased faster for drivers 1620 and slowest for drivers 35 and over. In addition, in every comparison, relative risk increased faster with increasing BAC for fatally injured drivers than for driver involvement in fatal crashes.

Figure 1. Relative fatality risk for drinking drivers by age and sex in single-vehicle crashes ${ }^{6}$

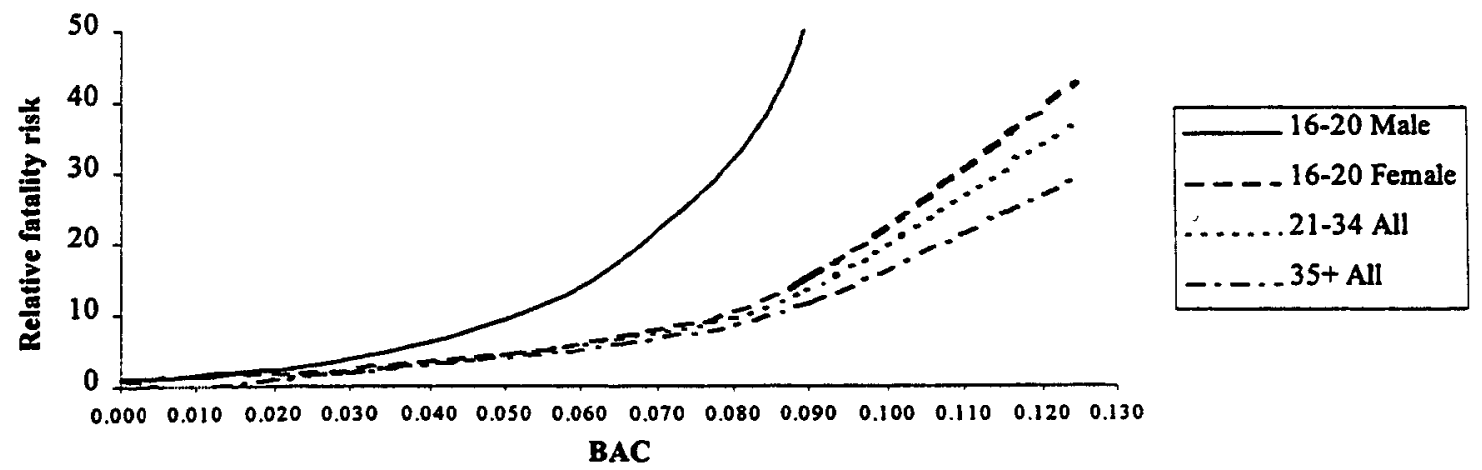

In general, the pattern of results for the other driver groups was quite similar to the pattern just described (see Tables 6.2 - 6.6). Figure 2 and Table 6.6 show a similar pattern for driver involvement in all fatal crashes. The following represent major differences among the other driver groups. (1) For fatally injured drivers, relative risk increased slower with increasing BAC in two vehicle than in single vehicle crashes. As indicated earlier, this was to be expected since in multi-vehicle fatal crashes, scatis involved drivers were likely to be no more than marginally at-fault. (2) Also, since most fatally injus:-: crivers were killed in a single vehicle or in a two vehicle crash, the overall rate of increase in relative risk was between the rates of increase for single vehicle and two vehicle crashes.

Figure 2. Relative risk for the involvement of drinking drivers by age and sex in all passenger vehicle crashes $^{7}$

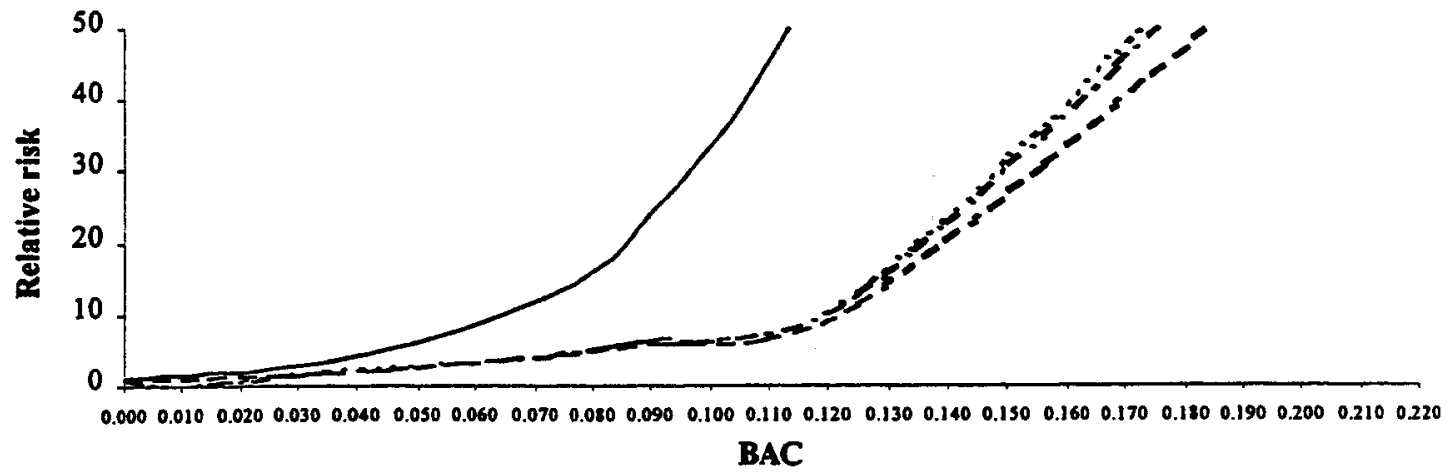

16-20 Male _ $\ldots-16-20$ Female ......21-34 All $\ldots \ldots \ldots 35+$ All

\footnotetext{
${ }^{6} \mathrm{BAC}$ values are the midpoints of the intervals depicted in Table 6.1.

Risks off scale for $\mathrm{BAC}=0.220: \quad 16-20$ Male $=15,560 ; 16-20$ Female $=738$;

21-34 All $=573 ; 35+$ All $=382$.

Risk off scale for $B A C=0.125 \quad 16-20 \quad$ Male $=241$.

Risk off scale for $\mathrm{BAC}=0.090 \quad 16-20$ Male $=52$.

${ }^{7}$ BAC values are the midpoints of the intervals depicted in Table 6.6.

Risks off scale for $\mathrm{BAC}=0.220: \quad 16-20$ Male $:=2,372 ; 16-20$ Female $=74$;

$\begin{array}{lll}\text { Risk off scale for } \mathrm{BAC}=0.125 & 21-34 \text { All }=88 ; 35 \text { All }=84 .\end{array}$
} 


\section{Discussion}

\section{Confirmatory Findings}

This study has confirmed that, in general, relative risks of fatal injury and fatal crash involvement both steadily increased with increasing driver BAC within each of the six driver age and sex groups studied. The only exception was that among drivers 21 and over, relative risk was lower at near-zero positive BAC than at zero BAC. The classical Grand Rapids study by Borkenstein et al. (1974) found a similar "dip" in the risk curve. Hurst (1973) showed that controlling self-reported drinking frequency eliminates the Grand Rapids dip. The customary interpretation of these results is that the anomalous dip probably results from differing alcohol tolerance between crash-involved and non-crash involved drivers. Since drinking frequency data were not available in our study, we were unable to estimate risk curves by drinking frequency. With few exceptions, relative risk was found to decrease with increasing driver age at every BAC level, both for males and for females - a finding that extends similar age trends reported for moderate BACs by Zador (1991).

The current study also confirms the substantially higher relative risk for involvement in a single vehicle crash of young drivers at a zero BAC previously reported by Mayhew et al. (1986). Overall, young drivers experienced higher relative risks of single vehicle crashes than did older drivers of the same sex. Additionally, female drivers exhibited substantially lower relative risk than male drivers of the same age. To a somewhat lesser extent, both sets of findings were also true for most of the other five driver groups studied.

In this study, lower and upper $95 \%$ confidence bound estimates for relative risk as a function of driver BAC take into account both the sampling variation of the roadside driver exposure sample, and the effect of multiple BAC imputations performed by Rubin et al. (1999) for NHTSA. Not surprisingly, relative risk confidence intervals are wide. For example, lower and upper confidence bounds were 16.5 and 164 for male drivers $16-20$ killed in single vehicle crashes with a BAC between $0.08 \%$ and $0.10 \%{ }^{8}$ We note that the width of $95 \%$ confidence intervals increases with increasing BACs for mathematical reasons. ' We also note that allowing for comparable variation in prior estimates, the relative risk estimates presented here are largely in line with estimates published elsewhere. ${ }^{10}$

\section{New Findings}

This is the first study that estimated relative risk from compatible data sources using the same methods for six driver groups of interest defined by the number of crash-involved vehicles and, whether the driver was just involved, or also fatally injured in the crash. Drivers killed in single vehicle crashes are of particular interest for assessing the pure effect of drinking and driving because in single vehicle crashes: driver fault is not shared, crash configuration is less of a factor, vehicle occupancy is not relevant, and the seating position of the fatally injured occupant is fixed. In two vehicle crashes, the possibility that fault may be split between two drivers, one or both of whom may have a (possibly different) positive $B A C$, would seem to make it difficult to estimate the pure effect of BAC on crash risk. It was all the more gratifying to find the relative risk of a fatal driver injury depend on driver $\mathrm{BAC}$ in

\footnotetext{
These relative risk estimates apply to BAC range mid-points at $0.09 \%$.

'Both relative risk and its confidence bounds depend exponentially on the corresponding logistic regression parameters.

${ }^{10}$ Relative risk estimates in this paper differ in several ways from similar estimates in Zador (1991): In the former study, the baseline BAC group was defined to include drivers at or below a BAC of $0.01 \%$, age groups and BAC groups were defined differently, driver fatalities were included from only 29 states with low rates of missing BACs, missing BACs were not imputed, and the numeric BAC values were not used in analyses except to classify drivers.
} 
almost the same way for single vehicle crashes as for two vehicie crashes provided that the relative risk model of two vehicle crashes statistically accounted for the possible roles of not at-fault sober drivers (see Appendix F). In this study, we focused on the general effect on relative risk of a positive driver BAC, rather than on its pure effect. Our main statistical model for estimating relative risk did not, therefore, adjust relative risk estimates for the over-representation of sober (probably not-at-fault) drivers. Consequently, the model we used in this study appears to have generally underestimated the pure effect of positive driver BAC on relative risk, except for drivers in single vehicle crashes.

As noted earlier, this study confirmed that relative risk and driver age are inversely related at every BAC. However, somewhat surprisingly in part contrary to Zador (1991), relative risk was found to be generally lower at all BAC levels for females than for males for the 16-20 group. This lower relative risk (roughly comparable to adult drivers 21 to 34 at BACs of $0.02 \%$ and over) is important because of the increasing incidence of drinking females in that age group in the nighttime driving population observed in the $90 \mathrm{NRS}$. In that most recent survey, there were more, but not significantly more, women drinking drivers in the 16-20 age group than males. Perhaps the lower relative risk could attributed to females driving more cautiously than their male age counterparts.

Finally, this study is the first that systematically estimated relative risk for drinking drivers with BACs between $0.08 \%$ and $0.10 \%,{ }^{11}$ and the relative risk estimates obtained here provide clear evidence that drinking and driving at BACs under $0.10 \%$ is very dangerous. For driver fatalities in single vehicle crashes with a BAC in this range, relative risk estimates ranged from a low of 11.4 for drivers 35 and over, to a high of 51.9 for male drivers under 21 , and even the lowest among the six lower confidence bounds indicated a nearly six fold rise in fatality risk. This similar pattern was also found overall (i.e., for any involvement in a fatal motor vehicle crash), although with smaller magnitudes. Drivers 35 and over had the lowest relative risk of involvement at about 6.1, followed by those in the 21-34 age group at 6.3. The youngest male age group had a relative risk of about 24 - four times that of the other age groups (Table 6.6 and Figure 2). Naturally, relative risk was considerably higher for drivers with a BAC between $0.10 \%$ and $0.15 \%$, and ranged between 29 for drivers 35 and over and 241 for male drivers under 21 for driver fatalities in single vehicle crashes. Relative risk for drinking drivers with a BAC at or above $0.15 \%$ ranged from 382 for drivers 35 and over, to 15,560 for male drivers under 21 .

\section{Policy Implications}

There is considerable evidence that lowering state BAC limits to $0.08 \%$ from $0.10 \%$ reduced fatal motor vehicle crashes (e.g., Hingson et al., 1996; Voas and Tippetts, 1999), and according to recent NHTSA information, 17 states plus the District of Columbia defined a driver BAC of $0.08 \%$ as illegal per se. New findings from this study lend support to lowering the illegal per se limit by showing that driving at BACs under $0.10 \%$ is indeed very dangerous. Additionally, an ongoing laboratory investigation at the Southern California Research Institute with participation by the first author of this study, has provided strong evidence that impairment of driving-related performance occurs at very low BAC levels even among experienced drinkers.

Obviously, baseline differences are important for comparing driver groups in absolute terms since overall crash risk is affected both by baseline risk differences among sober drivers, and by age- and sexrelated differences in the effects of drinking and driving. For example, when considering policy options for young drivers, it is important to bear in mind overall risk, not just sober-driving or drinking and driving risks. Since young male drivers in the 16-20 age group start from an already high baseline risk level in all driver groups (see Figure 3), even at slightly elevated BACs in the $0.02 \%-0.05 \%$ range, this

\footnotetext{
"These relative risk estimates apply to BAC range mid-points at $0.09 \%$.
} 
group experienced fatal driver injuries in single vehicle crashes more than eight times as often as sober male drivers 21-34. Policy measures designed to reduce drinking and driving and alcohol-related crashes in the youngest age group include the enforcement of minimum drinking age laws that prohibit the purchase of alcoholic beverages by persons under age 21, and the establishing and enforcing of near-zero $\mathrm{BAC}$ limits (zero tolerance) for drivers under 21. Complementary strategies designed to reduce both sober-driving and drinking and driving crashes among the youngest drivers include graduated licensure and young curfews (U.S. DOT, 1998).

Figure 3. Baseline risk at $\mathrm{BAC}=0$ relative to male $21-34$ group

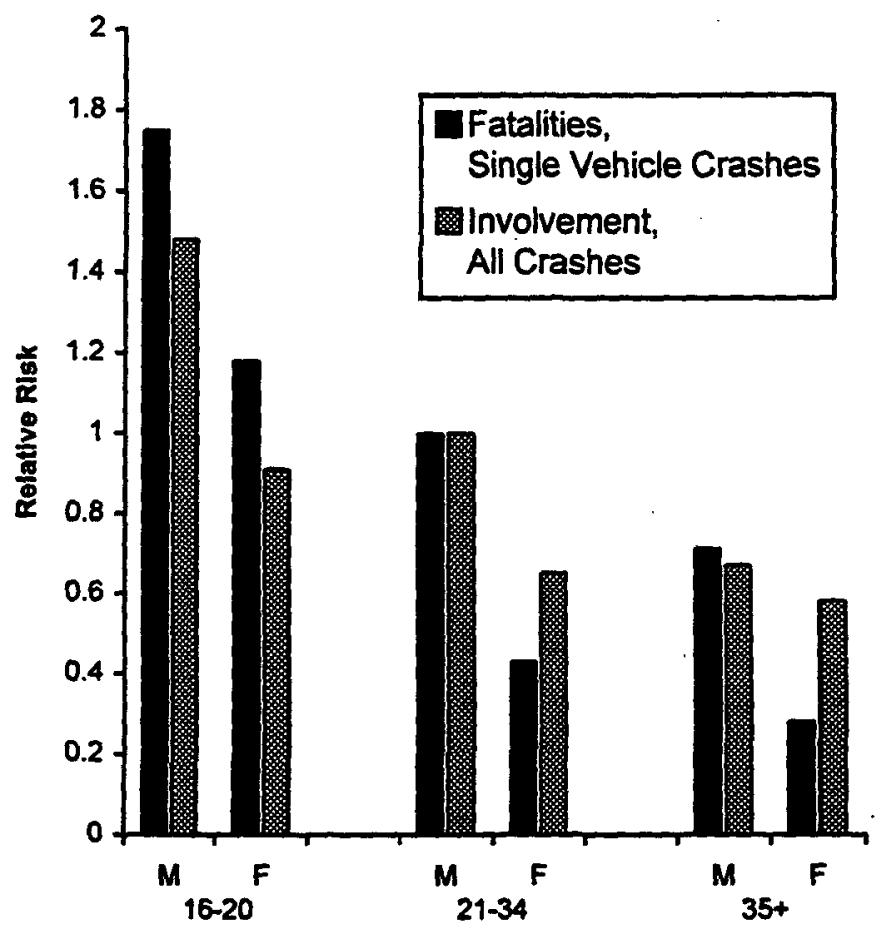

With the new findings of this study, and parallel results currently being observed in laboratory studies at the Southern California Research Institute, one can state with confidence that driving at nonzero BACs somewhat lower than $0.10 \%$ is indeed very dangerous. Thus, reducing BAC limits from $0.10 \%$ to $0.08 \%$ is an effective method of saving lives. Moreover, these results show that with such elevated relative risks, reducing drinking and driving at any $\mathrm{BAC}$ level is likely to further reduce alcoholrelated motor vehicle fatalities in the United States. 
Table 1.1. Exposure survey sample size $(\mathrm{N})$ and weighted percent distribution (\%) by sex, age, and $\mathrm{BAC}$ in the 48 contiguous states during weekend nights.

Data from 96 NRS.

\begin{tabular}{|c|c|c|c|c|c|c|c|c|c|c|c|c|c|c|c|c|c|}
\hline \multirow[b]{3}{*}{ Sex } & \multirow[b]{3}{*}{ Age } & \multicolumn{14}{|c|}{$B A C$} & \multirow{2}{*}{\multicolumn{2}{|c|}{ Total }} \\
\hline & & \multicolumn{2}{|c|}{000} & \multicolumn{2}{|c|}{$001-019$} & \multicolumn{2}{|c|}{$020-049$} & \multicolumn{2}{|c|}{$050-079$} & \multicolumn{2}{|c|}{$080-099$} & \multicolumn{2}{|c|}{$100-149$} & \multicolumn{2}{|c|}{$150+$} & & \\
\hline & & $N$ & $\%$ & $N$ & $\%$ & $N$ & $\%$ & $\mathrm{~N}$ & $\%$ & $\mathrm{~N}$ & $\%$ & $\mathbf{N}$ & $\%$ & $N$ & $\%$ & $\mathrm{~N}$ & $\%$ \\
\hline \multirow[t]{4}{*}{ Male } & $16-20$ & 566 & 9.9 & 16 & 0.3 & 26 & 0.2 & 10 & 0.1 & 5 & 0.2 & 1 & 0.0 & 1 & 0.0 & 625 & 10.6 \\
\hline & $21-34$ & 1,279 & 19.0 & 97 & 1.4 & 139 & 1.7 & 105 & 1.7 & 34 & 0.4 & 70 & 1.0 & 25 & 0.3 & 1,749 & 25.4 \\
\hline & $35 t$ & 1,292 & 24.0 & 86 & 1.4 & 90 & 1.4 & 44 & 0.6 & 31 & 0.3 & 32 & 0.6 & 19 & $\therefore$ & 1,594 & 28.5 \\
\hline & All & 3,137 & 52.9 & 199 & 3.0 & 255 & 3.3 & 159 & 2.3 & 70 & 0.9 & 103 & 1.6 & 45 & 1.5 & 3,968 & 64.6 \\
\hline \multirow[t]{4}{*}{ Fernale } & $16-20$ & 303 & 6.6 & 7 & 0.1 & 7 & 0.3 & 6 & 0.2 & 3 & 0.0 & 3 & 0.0 & 0 & 0.0 & 329 & 7.2 \\
\hline & $21-34$ & 617 & 11.9 & 32 & 0.5 & 72 & 0.9 & 37 & 0.6 & 15 & 02 & 18 & 0.3 & 3 & 0.0 & 794 & 14.4 \\
\hline & $35+$ & 643 & 12.1 & 27 & 0.5 & 28 & 0.6 & 12 & 0.2 & 8 & 02 & 10 & 0.2 & 1 & 0.0 & 729 & 13.7 \\
\hline & All & 1,563 & 30.6 & 66 & 1.1 & 107 & 1.7 & 55 & 0.9 & 26 & 0.5 & 31 & 0.5 & 4 & 0.0 & 1,852 & 35.4 \\
\hline \multirow[t]{4}{*}{ All } & $16-20$ & 869 & 16.5 & 23 & 0.4 & 33 & 0.5 & 16 & 0.3 & 8 & 0.2 & 4 & 0.0 & 1 & 0.0 & 954 & 17.9 \\
\hline & $21-34$ & 1,896 & 30.9 & 129 & 1.9 & 211 & 2.6 & 142 & 2.3 & 49 & 0.7 & 88 & 1.2 & 28 & 0.3 & 2,543 & 39.8 \\
\hline & $35+$ & 1,935 & 36.1 & 113 & 1.9 & 118 & 1.9 & 56 & 0.7 & 39 & 0.5 & 42 & 0.8 & 20 & 0.3 & 2,323 & 42.3 \\
\hline & All & 4,700 & 83.5 & 265 & 4.1 & 362 & 5.1 & 214 & 3.3 & 96 & 1.4 & 134 & 2.1 & 49 & 0.6 & 5,820 & 100.0 \\
\hline
\end{tabular}

Table 1.2. Frequency $(\mathrm{N})$ and percent distribution (\%) of driver fatalities in single vehicle crashes by sex, age, and BAC in the 48 contiguous states diring weekend nights.

Data from FARS, years 95-96.

\begin{tabular}{|c|c|c|c|c|c|c|c|c|c|c|c|c|c|c|c|c|c|}
\hline \multirow[b]{3}{*}{ Sex } & \multirow[b]{3}{*}{ Age } & \multicolumn{14}{|c|}{ BAC } & \multirow{2}{*}{\multicolumn{2}{|c|}{ Total }} \\
\hline & & \multicolumn{2}{|c|}{000} & \multicolumn{2}{|c|}{$001-019$} & \multicolumn{2}{|c|}{$020-049$} & \multicolumn{2}{|c|}{$050-079$} & \multicolumn{2}{|c|}{ 080-099 } & \multicolumn{2}{|c|}{$100-149$} & \multicolumn{2}{|c|}{$150+$} & & \\
\hline & & $\mathbf{N}$ & $\%$ & $\mathbf{N}$ & $\%$ & $\mathbf{N}$ & $\%$ & $\mathbf{N}$ & $\%$ & $\mathbf{N}$ & $\%$ & $\mathbf{N}$ & $\%$ & $N$ & $\%$ & $\mathbf{N}$ & $\%$ \\
\hline \multirow[t]{4}{*}{ Male } & $16-20$ & 113 & 4.4 & 3 & 0.1 & 21 & 0.8 & 27 & 1.1 & 26 & 1.0 & 89 & 3.5 & 156 & 6.1 & 435 & 17.0 \\
\hline & $21-34$ & 124 & 4.9 & 1 & 0.0 & 15 & 0.6 & 41 & 1.6 & 41 & 1.6 & 200 & 7.8 & 619 & 24.3 & 1,041 & 40.8 \\
\hline & $35-97$ & 111 & 4.3 & 0 & 0.0 & 11 & 0.4 & 16 & 0.6 & 17 & 0.7 & 84 & 3.3 & 420 & 16.5 & 659 & 25.8 \\
\hline & Al! & 348 & 13.6 & 4 & 0.2 & 47 & 1.8 & 84 & 3.3 & 84 & 3.3 & 373 & 14.6 & 1,195 & 46.8 & 2,135 & 83.7 \\
\hline \multirow[t]{4}{*}{ Female } & $16-20$ & 51 & 2.0 & 3 & 0.1 & 4 & 02 & 6 & 0.2 & 2 & 0.1 & 11 & 0.4 & 15 & 0.6 & 92 & 3.6 \\
\hline & $21-34$ & 33 & 1.3 & 0 & 0.0 & 2 & 0.1 & 11 & 0.4 & 10 & 0.4 & 36 & 1.4 & 99 & 3.9 & 191 & 7.5 \\
\hline & $35-97$ & 22 & 0.9 & 0 & 0.0 & 3 & 0.1 & 4 & 0.2 & 6 & 0.2 & 15 & 0.6 & 84 & 3.3 & 134 & 53 \\
\hline & All & 106 & 4.2 & 3 & 0.1 & 9 & 0.4 & 21 & 0.8 & 18 & 0.7 & 62 & 2.4 & 198 & 7.8 & 417 & 16.3 \\
\hline \multirow[t]{4}{*}{ All } & $16-20$ & 164 & 6.4 & 6 & 0.2 & 25 & 1.0 & 33 & 13 & 28 & 1.1 & 100 & 3.9 & 171 & 6.7 & 527 & 20.7 \\
\hline & $21-34$ & 157 & 6.2 & 1 & 0.0 & 17 & 0.7 & 52 & 2.0 & 51 & 2.0 & 236 & 92 & 718 & 28.1 & 1,232 & 48.3 \\
\hline & $35-97$ & 133 & 52 & 0 & 0.0 & 14 & 0.5 & 20 & 0.8 & 23 & 0.9 & 99 & 3.9 & 504 & 19.7 & 793 & 31.1 \\
\hline & All & 454 & 17.8 & 7 & 0.3 & 56 & 22 & 105 & 4.1 & 102 & 4.0 & 435 & 17.0 & 1,393 & 54.6 & 2,552 & 100.0 \\
\hline
\end{tabular}


Table 2. Relative risk and relative risk confidence bound estimates for fatalities and fatal crash involvement at zero driver BAC by the number of crash-involved vehicles, sex, and age, using male drivers aged $21-34$ as the baseline.

Data from the 96NRS and FARS, years 95-96.

\begin{tabular}{|c|c|c|c|c|c|c|c|c|}
\hline \multirow[b]{4}{*}{ Sex } & \multirow[b]{4}{*}{ Age } & & \multicolumn{6}{|c|}{ Number of vehicles in fatal crash } \\
\hline & & & \multicolumn{2}{|c|}{ Single vehicle } & \multicolumn{2}{|c|}{ Two vehicle } & \multirow{2}{*}{\multicolumn{2}{|c|}{$\frac{\text { Any }}{\text { Injury }}$}} \\
\hline & & & \multicolumn{2}{|c|}{ Injury } & \multicolumn{2}{|c|}{ Injury } & & \\
\hline & & & Fatal & Involv. & Fatal & Involv. & Fatal & Involv. \\
\hline \multirow[t]{9}{*}{ Male } & $16-20$ & Relative risk & 1.75 & 1.89 & 1.44 & 1.23 & 1.52 & 1.48 \\
\hline & & Lower & 1.33 & 1.58 & 1.05 & 1.02 & 1.23 & 1.29 \\
\hline & & Upper & 2.30 & 2.27 & 1.98 & 1.48 & 1.88 & 1.71 \\
\hline & $21-34$ & Relative risk & 1.00 & 1.00 & 1.00 & 1.00 & 1.00 & 1.00 \\
\hline & & Lower & 1.00 & 1.00 & 1.00 & 1.00 & 1.00 & 1.00 \\
\hline & & Upper & 1.00 & 1.00 & 1.00 & 1.00 & 1.00 & 1.00 \\
\hline & $35+$ & Relative risk & 0.71 & 0.61 & 0.90 & 0.69 & 0.81 & 0.67 \\
\hline & & Lower & 0.54 & 0.51 & 0.68 & 0.59 & 0.67 & 0.59 \\
\hline & & Upper & 0.93 & 0.73 & 1.19 & 0.82 & 0.98 & 0.76 \\
\hline \multirow[t]{9}{*}{ Female } & $16-20$ & Relative risk & 1.18 & 1.04 & 0.89 & 0.80 & 1.02 & 0.91 \\
\hline & & Lower & 0.83 & 0.82 & 0.58 & 0.63 & 0.78 & 0.76 \\
\hline & & Upper & 1.67 & 1.32 & 1,35 & 1.01 & 1.33 & 1.08 \\
\hline & $21-34$ & Relative risk & 0.43 & 0.63 & 0.67 & 0.59 & 0.57 & 0.65 \\
\hline & & Lower & 0.29 & 0.51 & 0.46 & 0.48 & 0.44 & 0.56 \\
\hline & & Upper & 0.63 & 0.79 & 0.98 & 0.73 & 0.75 & 0.76 \\
\hline & $35+$ & Relative risk & 0.28 & 0.39 & 1.10 & 0.69 & 0.62 & 0.58 \\
\hline & & Lower & 0.18 & 0.31 & 0.80 & 0.56 & 0.48 & 0.49 \\
\hline & & Upper & 0.44 & 0.51 & 1.51 & 0.84 & 0.80 & 0.68 \\
\hline
\end{tabular}

Table 3. Regression diagnostics for logistic regression models for fatality risk and fatal crash involvement risk by the number of crash-involved vehicles.

Data from the 96NRS and FARS, years 95-96.

\begin{tabular}{lcccccc}
\hline & \multicolumn{5}{c}{ Number of vehicles in fatal crash } \\
\cline { 2 - 7 } & \multicolumn{2}{c}{ Single vehicle } & \multicolumn{2}{c}{ Two vehicle } & \multicolumn{2}{c}{ Any } \\
\cline { 2 - 7 } Diagnostic & \multicolumn{2}{c}{ Injury } & \multicolumn{2}{c}{ Injury } & Injury \\
\cline { 2 - 7 } & Fatal & Involv. & Fatal & Involv. & Fatal & Involv. \\
\hline Heterogeneity factor & 1.6979 & 1.7774 & 1.8783 & 3.3159 & 2.0918 & 3.7070 \\
Max-rescaled rsquare & 0.6844 & 0.4935 & 0.6524 & 0.3142 & 0.5297 & 0.3171 \\
H-L goodness-of-fit, $\mathrm{p}$ & $\mathbf{0 . 1 9 9 8}$ & 0.6806 & 0.0317 & $\mathbf{0 . 0 0 0 1}$ & 0.4008 & 0.0002 \\
Normality of residuals, $\mathrm{p}$ & $\mathbf{0 . 2 8 1 3}$ & 0.0606 & 0.5701 & $\mathbf{0 . 4 1 7 5}$ & $\mathbf{0 . 2 1 8 9}$ & $\mathbf{0 . 0 1 6 5}$ \\
\hline
\end{tabular}


Table 4. The effect of BAC, sex, and age on fatality risk and fatal crash involvement risk estimates based on logistic regression models by the number of crash-involved vehicles.

Data from the 96NRS and FARS, years 95-96.

\begin{tabular}{|c|c|c|c|c|c|c|c|}
\hline \multirow[b]{4}{*}{ Parameter } & & \multicolumn{6}{|c|}{ Number of vehicles in fatal crash } \\
\hline & & \multirow{2}{*}{\multicolumn{2}{|c|}{$\frac{\text { Single vehicle }}{\text { Injury }}$}} & \multirow{2}{*}{\multicolumn{2}{|c|}{$\begin{array}{c}\text { Two vehicle } \\
\text { Injury }\end{array}$}} & \multirow{2}{*}{\multicolumn{2}{|c|}{$\frac{\text { Any }}{\text { Injury }}$}} \\
\hline & & & & & & & \\
\hline & & Fatal & Involv. & Fatal & Involv. & Fatal & Involv. \\
\hline \multirow[t]{2}{*}{ Age $16-20$} & Regression coefficient & -1.547 & -0.572 & -2.184 & -0.873 & -1.077 & 0.085 \\
\hline & Standard error of R.C. & 0.072 & 0.063 & 0.060 & 0.057 & 0.065 & 0.057 \\
\hline \multirow[t]{2}{*}{ Age $21-34$} & Regression coefficient & -2.352 & -1.205 & -2.643 & -1.187 & -1.654 & -0.331 \\
\hline & Standard error of R.C. & 0.042 & 0.028 & 0.051 & 0.034 & 0.036 & 0.025 \\
\hline \multirow[t]{2}{*}{ Age 35+ } & Regression coefficient & -2.540 & -1.656 & -2.425 & -1.291 & -1.672 & -0.591 \\
\hline & Standard error of R.C. & 0.043 & 0.039 & 0.037 & 0.036 & 0.036 & 0.039 \\
\hline \multirow[t]{2}{*}{ Female } & Regression coefficient & -0.580 & -0.509 & -0.065 & -0.265 & -0.351 & -0.356 \\
\hline & Standard error of R.C. & 0.069 & 0.053 & 0.054 & 0.043 & 0.053 & 0.042 \\
\hline \multirow[t]{2}{*}{$\mathrm{BAC}=000-019$, Age $21+$} & Regression coefficient & -2.861 & -1.889 & -1.593 & -2.004 & -2.031 & -1.925 \\
\hline & Standard error of R.C. & 0.375 & 0.126 & 0.121 & 0.134 & 0.137 & 0.106 \\
\hline \multirow[t]{2}{*}{ BAC, Age $16-20$} & Regression cosfiticient & 0.044 & 0.039 & 0.032 & 0.031 & 0.041 & 0.035 \\
\hline & Standard error: tr R.C. & 0.007 & 0.006 & 0.005 & 0.005 & 0.006 & 0.005 \\
\hline \multirow{2}{*}{ BAC, Age 16-20, Female } & Regression coefificient & -0.014 & -0.015 & -0.006 & -0.015 & -0.016 & -0.016 \\
\hline & Standard error of R.C. & 0.006 & 0.005 & 0.006 & 0.005 & 0.006 & 0.005 \\
\hline \multirow[t]{2}{*}{ BAC, Age 21-34 } & Regression coefficient & 0.029 & 0.024 & 0.023 & 0.019 & 0.026 & 0.020 \\
\hline & Standard error of R.C. & 0.001 & 0.001 & 0.001 & 0.001 & 0.001 & 0.001 \\
\hline \multirow[t]{2}{*}{ BAC, Age 35+ } & Regression coefficient & 0.027 & 0.024 & 0.020 & 0.018 & 0.023 & 0.020 \\
\hline & Standard error of R.C. & 0.001 & 0.001 & 0.001 & 0.001 & 0.001 & 0.001 \\
\hline
\end{tabular}

Negative parameters have the effect of reducing the relative risk.

Positive parameters increase the relative risk.

Table 5. Model-based estimate for factor of proportionate increase (FPI) in relative fatality risk and relative involvement risk associated with $a .02 \%$ increase in $\mathrm{BAC}$ by the number of crashinvolved vehicles, sex, and age.

Data from the 96NRS and FARS, years 95-96.

\begin{tabular}{|c|c|c|c|c|c|c|c|}
\hline & & \multicolumn{6}{|c|}{ Number of vehicles in fatal crash } \\
\hline & & \multicolumn{2}{|c|}{ Single vehicle } & \multicolumn{2}{|c|}{ Two vehicle } & \multicolumn{2}{|c|}{ Any } \\
\hline & & \multicolumn{2}{|c|}{ Injury } & \multicolumn{2}{|c|}{ Injury } & \multicolumn{2}{|c|}{ Injury } \\
\hline & & Fatal & Involvement & Fatal & Involvement & Fatal & Involvement \\
\hline Sex & Age & FPI & FPI & FPI & FPI & FPI & FPI \\
\hline \multirow[t]{3}{*}{ Male } & $16-20$ & 2.41 & 2.17 & 1.94 & 1.84 & 2.29 & 2.01 \\
\hline & $21-34$ & 1.78 & 1.62 & 1.56 & 1.45 & 1.66 & 1.51 \\
\hline & $35+$ & 1.73 & 1.62 & 1.49 & 1.44 & 1.61 & 1.50 \\
\hline \multirow[t]{3}{*}{ Female } & $16-20$ & 1.80 & 1.63 & 1.71 & 1.39 & 1.65 & 1.47 \\
\hline & $21-34$ & 1.78 & 1.62 & 1.56 & 1.45 & 1.66 & 1.51 \\
\hline & $35+$ & 1.73 & 1.62 & 1.49 & 1.44 & 1.61 & 1.50 \\
\hline
\end{tabular}


Table 6.1. Model-based relative driver facility risk and risk confidence bound estimates for single vehicle crashes by $B A C$, sex, and age, using zero $B A C$ as the baseline.

Data from the 96NRS and FARS, years 95-96.

\begin{tabular}{|c|c|c|c|c|c|c|c|c|c|}
\hline \multirow[b]{2}{*}{ Sex } & \multirow[b]{2}{*}{ Age } & & \multicolumn{7}{|c|}{ BAC } \\
\hline & & & 000 & $001-019$ & $020-049$ & $050-079$ & 080-099 & $100-149$ & $150+$ \\
\hline \multirow[t]{9}{*}{ Male } & $16-20$ & Relative risk & 1.00 & 1.55 & 4.64 & 17.32 & 51.87 & 240.89 & $15,559.85$ \\
\hline & & Lower & 1.00 & 1.36 & 2.97 & 7.56 & 16.45 & 48.87 & 939.22 \\
\hline & & Upper & 1.00 & 1.76 & 7.26 & 39.70 & 163.57 & $1,187.33$ & $257,777.67$ \\
\hline & $21-34$ & Relative risk & 1.00 & 0.08 & 2.75 & 6.53 & 13.43 & 36.89 & 572.55 \\
\hline & & Lower & 1.00 & 0.04 & 2.53 & 5.61 & 10.89 & 27.57 & 342.99 \\
\hline & & Upper & 1.00 & 0.16 & 2.98 & 7.60 & 16.57 & 49.36 & 955.76 \\
\hline & $35+$ & Relative risk & 1.00 & 0.07 & 2.57 & 5.79 & 11.38 & 29.30 & 381.68 \\
\hline & & Lower & 1.00 & 0.04 & 2.34 & 4.84 & 8.87 & 20.73 & 207.56 \\
\hline & & Upper & 1.00 & 0.16 & 2.84 & 6.93 & 14.60 & 41.42 & 701.86 \\
\hline \multirow[t]{9}{*}{ Female } & $16-20$ & Relative risk & 1.00 & 1.35 & 2.86 & 7.04 & 14.91 & 42.63 & 738.36 \\
\hline & & Lower & 1.00 & 1.21 & 1.96 & 3.50 & 5.68 & 11.15 & 69.67 \\
\hline & & Upper & 1.00 & 1.50 & 4.16 & 14.14 & 39.15 & 163.01 & $7,824.89$ \\
\hline & $21-34$ & Relative risk & 1.00 & 0.08 & 2.75 & 6.53 & 13.43 & 36.89 & 572.55 \\
\hline & & Lower & 1.00 & 0.04 & 2.53 & 5.61 & 10.89 & 27.57 & 342.99 \\
\hline & & Upper & 1.00 & 0.16 & 2.98 & 7.60 & 16.57 & 49.36 & 955.76 \\
\hline & $35+$ & Relative risk & 1.00 & 0.07 & 2.57 & 5.79 & 11.38 & 29.30 & 381.68 \\
\hline & & Lower & 1.00 & 0.04 & 2.34 & 4.84 & 8.87 & 20.73 & 207.56 \\
\hline & & Upper & 1.00 & 0.16 & 2.84 & 6.93 & 14.60 & 41.42 & 701.86 \\
\hline
\end{tabular}

Table 6.2. Model-based relative driver involvement risk and risk confidence bound estimates for single vehicle crashes by $\mathrm{BAC}$, sex, and age, using zero BAC as the baseline. Data from the 96NRS and FARS, years 95-96.

\begin{tabular}{|c|c|c|c|c|c|c|c|c|c|}
\hline \multirow[b]{2}{*}{ Sex } & \multirow[b]{2}{*}{ Age } & & \multicolumn{7}{|c|}{ BAC } \\
\hline & & & 000 & $001-019$ & $020-049$ & $050-079$ & 080-099 & $100-149$ & $150+$ \\
\hline \multirow[t]{9}{*}{ Male } & $16-20$ & Relative risk & 1.00 & 1.48 & 3.92 & 12.63 & 33.50 & 131.26 & $5,344.67$ \\
\hline & & Lower & 1.00 & 1.32 & 2.63 & 6.03 & 12.05 & 31.71 & 438.76 \\
\hline & & Upper & 1.00 & 1.66 & 5.83 & 26.44 & 93.16 & 543.26 & $65,105.68$ \\
\hline & $21-34$ & Relative risk & 1.00 & 0.19 & 2.32 & 4.75 & 8.66 & 20.04 & 195.67 \\
\hline & & Lower & 1.00 & 0.15 & 2.14 & 4.12 & 7.09 & 15.19 & 120.13 \\
\hline & & Upper & 1.00 & 0.25 & 2.50 & 5.49 & 10.57 & 26.45 & 318.72 \\
\hline & $35 t$ & Relative risk & 1.00 & 0.19 & 2.31 & 4.72 & 8.58 & 19.78 & 191.19 \\
\hline & & Lower & 1.00 & 0.15 & 2.08 & 3.91 & 6.61 & 13.79 & 101.31 \\
\hline & & Upper & 1.00 & 0.25 & 2.55 & 5.70 & 11.12 & 28.38 & 360.83 \\
\hline \multirow[t]{9}{*}{ Female } & $16-20$ & Relative risk & 1.00 & 1.28 & 2.35 & 4.89 & 9.00 & 21.16 & 215.25 \\
\hline & & Lower & 1.00 & 1.15 & 1.61 & 2.43 & 3.41 & 5.51 & 20.13 \\
\hline & & Upper & 1.00 & 1.42 & 3.43 & 9.85 & 23.74 & 81.33 & $2,301.88$ \\
\hline & $21-34$ & Relative risk & 1.00 & 0.19 & 2.32 & 4.75 & 8.66 & 20.04 & 195.67 \\
\hline & & Lower & 1.00 & 0.15 & 2.14 & 4.12 & 7.09 & 15.19 & 120.13 \\
\hline & & Upper & 1.00 & 0.25 & 2.50 & 5.49 & 10.57 & 26.45 & 318.72 \\
\hline & $35+$ & Relative risk & 1.00 & 0.19 & 2.31 & 4.72 & 8.58 & 19.78 & 191.19 \\
\hline & & Lower & 1.00 & 0.15 & 2.08 & 3.91 & 6.61 & 13.79 & 101.31 \\
\hline & & Upper & 1.00 & 0.25 & 2.55 & 5.70 & 11.12 & 28.38 & 360.83 \\
\hline
\end{tabular}


Table 6.3. Model-based relative driver fatality risk and risk confidence bound estimates for two vehicle crashes by $\mathrm{BAC}$, sex, and age, using zero $\mathrm{BAC}$ as the baseline.

Data from the 9NRS and FARS, years 95-96.

\begin{tabular}{|c|c|c|c|c|c|c|c|c|c|}
\hline \multirow[b]{2}{*}{ Sex } & \multirow[b]{2}{*}{ Age } & & \multicolumn{7}{|c|}{$\mathrm{BAC}$} \\
\hline & & & 000 & $001-019$ & $020-049$ & $050-079$ & 080-099 & $100-149$ & $150+$ \\
\hline \multirow[t]{9}{*}{ Male } & $16-20$ & Relative risk & 1.00 & 1.37 & 3.02 & 7.79 & 17.14 & 51.76 & $1,039.05$ \\
\hline & & Lower & 1.00 & 1.24 & 2.12 & 4.04 & 6.91 & 14.65 & 112.69 \\
\hline & & Upper & 1.00 & 1.52 & 4.30 & 15.01 & 42.54 & 182.88 & $9,580.91$ \\
\hline & $21-34$ & Relative risk & 1.00 & 0.25 & 2.20 & 4.33 & 7.60 & 16.72 & 142.20 \\
\hline & & Lower & 1.00 & 0.20 & 2.06 & 3.83 & 6.41 & 13.21 & 93.90 \\
\hline & & Upper & 1.00 & 0.33 & 2.35 & 4.89 & 9.00 & 21.17 & 215.36 \\
\hline & $35+$ & Relative risk & 1.00 & 0.25 & 1.98 & 3.55 & 5.79 & 11.46 & 73.13 \\
\hline & & Lower & 1.00 & 0.19 & 1.83 & 3.07 & 4.72 & 8.63 & 44.41 \\
\hline & & Upper & 1.00 & 0.32 & 2.14 & 4.12 & 7.10 & 15.21 & 120.43 \\
\hline \multirow[t]{9}{*}{ Female } & $16-20$ & Relative risk & 1.00 & 1.29 & 2.43 & 5.21 & 9.84 & 23.95 & 267.58 \\
\hline & & Lower & 1.00 & 1.16 & 1.70 & 2.67 & 3.91 & 6.63 & 27.94 \\
\hline & & Upper & 1.00 & 1.43 & 3.49 & 10.16 & 24.80 & 86.44 & $2,562.25$ \\
\hline & $21-34$ & Relative risk & 1.00 & 0.25 & 2.20 & 4.33 & 7.60 & 16.72 & 142.20 \\
\hline & & Lower & 1.00 & 0.20 & 2.06 & 3.83 & 6.41 & 13.21 & 93.90 \\
\hline & & Upper & 1.00 & 0.33 & 2.35 & 4.89 & 9.00 & 21.17 & 215.36 \\
\hline & $35+$ & Relative risk & 1.00 & 0.25 & 1.98 & 3.55 & 5.79 & 11.46 & 73.13 \\
\hline & & Lower & 1.00 & 0.19 & 1.83 & 3.07 & 4.72 & 8.63 & 44.41 \\
\hline & & Upper & 1.00 & 0.32 & 2.14 & 4.12 & 7.10 & 15.21 & 120.43 \\
\hline
\end{tabular}

Table 6.4. Model-based relative driver involvement risk and risk confidence bound estimates for two vehicle crashes by $\mathrm{BAC}$, sex, and age, using zero $\mathrm{BAC}$ as the baseline. Data from the 96NRS and FARS, years 95-96.

\begin{tabular}{|c|c|c|c|c|c|c|c|c|c|}
\hline \multirow[b]{2}{*}{ Sex } & \multirow[b]{2}{*}{ Age } & & \multicolumn{7}{|c|}{$\mathrm{BAC}$} \\
\hline & & & 000 & 001-019 & 020-049 & 050-079 & 080-099 & $100-149$ & $150+$ \\
\hline \multirow[t]{9}{*}{ Male } & $16-20$ & Relative risk & 1.00 & 1.36 & 2.93 & 7.38 & 15.91 & 46.68 & 866.22 \\
\hline & & Lower & 1.00 & 1.22 & 2.03 & 3.72 & 6.16 & 12.49 & 85.12 \\
\hline & & Upper & 1.00 & 1.51 & 4.24 & 14.64 & 41.11 & 174.42 & $8,814.92$ \\
\hline & $21-34$ & Relative risk & 1.00 & 0.16 & 1.92 & 3.37 & 5.37 & 10.31 & 60.77 \\
\hline & & Lower & 1.00 & 0.12 & 1.79 & 2.96 & 4.49 & 8.04 & 39.23 \\
\hline & & Upper & 1.00 & 0.21 & 2.06 & 3.83 & 6.42 & 13.23 & 94.13 \\
\hline & $35+$ & Relative risk & 1.00 & 0.16 & 1.88 & 3.23 & 5.07 & 9.54 & 52.96 \\
\hline & & Lower & 1.00 & 0.12 & 1.70 & 2.68 & 3.92 & 6.67 & 28.18 \\
\hline & & Upper & 1.00 & 0.21 & 2.08 & 3.89 & 6.57 & 13.65 & 99.51 \\
\hline \multirow[t]{9}{*}{ Female } & $16-20$ & Relative risk & 1.00 & 1.17 & 1.74 & 2.79 & 4.15 & 7.22 & 32.40 \\
\hline & & Lower & 1.00 & 1.08 & 1.30 & 1.63 & 1.96 & 2.55 & 5.21 \\
\hline & & Upper & 1.00 & 1.27 & 2.33 & 4.80 & 8.77 & 20.39 & 201.63 \\
\hline & $21-34$ & Relative risk & 1.00 & 0.16 & 1.92 & 3.37 & 5.37 & 10.31 & 60.77 \\
\hline & & Lower & 1.00 & 0.12 & 1.79 & 2.96 & 4.49 & 8.04 & 39.23 \\
\hline & & Upper & 1.00 & 0.21 & 2.06 & 3.83 & 6.42 & 13.23 & 94.13 \\
\hline & $35+$ & Relative risk & 1.00 & 0.16 & 1.88 & 3.23 & 5.07 & 9.54 & 52.96 \\
\hline & & Lower & 1.00 & 0.12 & 1.70 & 2.68 & 3.92 & 6.67 & 28.18 \\
\hline & & Upper & 1.00 & 0.21 & 2.08 & 3.89 & 6.57 & 13.65 & 99.51 \\
\hline
\end{tabular}


Table 6.5. Model-based relative driver fatality risk and risk confidence bound estimates for all passenger vehicle crashes by $\mathrm{BAC}$, sex, and age, using zero $\mathrm{BAC}$ as the baseline. Data from the 90NRS and FARS, years 95-96.

\begin{tabular}{|c|c|c|c|c|c|c|c|c|c|}
\hline \multirow[b]{2}{*}{ Sex } & \multirow[b]{2}{*}{ Age } & & \multicolumn{7}{|c|}{$\mathrm{BAC}$} \\
\hline & & & 000 & $001-019$ & $020-049$ & $050-079$ & $080-099$ & $100-149$ & $150+$ \\
\hline \multirow[t]{9}{*}{ Male } & $16-20$ & Relative risk & 1.00 & 1.51 & 4.19 & 14.33 & 39.91 & 167.42 & $8,201.40$ \\
\hline & & Lower & 1.00 & 1.33 & 2.71 & 6.37 & 13.00 & 35.24 & 528.22 \\
\hline & & Upper & 1.00 & 1.71 & 6.49 & 32.23 & 122.57 & 795.33 & $127,338.85$ \\
\hline & $21-34$ & Relative risk & 1.00 & 0.17 & 2.44 & 5.26 & 9.95 & 24.31 & 274.87 \\
\hline & & Lower & 1.00 & 0.13 & 2.27 & 4.57 & 8.19 & 18.55 & 170.71 \\
\hline & & Upper & 1.00 & 0.22 & 2.64 & 6.05 & 12.09 & 31.87 & 442.58 \\
\hline & $35+$ & Relative risk & 1.00 & 0.17 & 2.26 & 4.56 & 8.18 & 18.51 & 170.13 \\
\hline & & Lower & 1.00 & 0.13 & 2.06 & 3.82 & 6.41 & 13.19 & 93.73 \\
\hline & & Upper & 1.00 & 0.22 & 2.49 & 5.44 & 10.44 & 25.98 & 308.81 \\
\hline \multirow[t]{9}{*}{ Female } & $16-20$ & Relative risk & 1.00 & 1.28 & 2.40 & 5.09 & 9.52 & 22.85 & 246.47 \\
\hline & & Lower & 1.00 & 1.16 & 1.70 & 2.69 & 3.94 & 6.72 & 28.58 \\
\hline & & Upper & 1.00 & 1.42 & 3.38 & 9.62 & 22.97 & 77.73 & $2,125.42$ \\
\hline & $21-34$ & Relative risk & 1.00 & 0.17 & 2.44 & 5.26 & 9.95 & 24.31 & 274.87 \\
\hline & & Lower & 1.00 & 0.13 & 2.27 & 4.57 & 8.19 & 18.55 & 170.71 \\
\hline & & Upper & 1.00 & 0.22 & 2.64 & 6.05 & 12.09 & 31.87 & 442.58 \\
\hline & $35+$ & Relative risk & 1.00 & 0.17 & 2.26 & 4.56 & 8.18 & 18.51 & 170.13 \\
\hline & & Lower & 1.00 & 0.13 & 2.06 & 3.82 & 6.41 & 13.19 & 93.73 \\
\hline & & Upper & 1.00 & 0.22 & 2.49 & 5.44 & 10.44 & 25.98 & 308.81 \\
\hline
\end{tabular}

Table 6.6. Model-based relative driver involvement risk and risk confidence estimates for all passenger vehicle crashes by $\mathrm{BAC}$, sex, and age, using zero $\mathrm{BAC}$ as the baseline.

Data from the 90NRS and FARS, years 95-96.

\begin{tabular}{|c|c|c|c|c|c|c|c|c|c|}
\hline \multirow[b]{2}{*}{ Sex } & \multirow[b]{2}{*}{ Age } & & \multicolumn{7}{|c|}{$\overline{\mathrm{BAC}}$} \\
\hline & & & 000 & $001-019$ & $020-049$ & $050-079$ & $080-099$ & $100-149$ & $150+$ \\
\hline \multirow[t]{9}{*}{ Male } & $16-20$ & Relative risk & 1.00 & 1.42 & 3.44 & 9.94 & 24.03 & 82.73 & $2,371.74$ \\
\hline & & Lower & 1.00 & 1.28 & 2.37 & 4.98 & 9.23 & 21.91 & 228.91 \\
\hline & & Upper & 1.00 & 1.58 & 4.99 & 19.82 & 62.53 & 312.31 & $24,574.14$ \\
\hline & $21-34$ & Relative risk & 1.00 & 0.18 & 2.04 & 3.76 & 6.25 & 12.74 & 88.13 \\
\hline & & Lower & 1.00 & 0.14 & 1.90 & 3.28 & 5.18 & 9.81 & 55.68 \\
\hline & & Upper & 1.00 & 0.22 & 2.19 & 4.30 & 7.54 & 16.54 & 139.51 \\
\hline & $35+$ & Relative risk & 1.00 & 0.18 & 2.02 & 3.70 & 6.13 & 12.41 & 84.13 \\
\hline & & Lower & 1.00 & 0.14 & 1.83 & 3.06 & 4.71 & 8.61 & 44.19 \\
\hline & & Upper & 1.00 & 0.22 & 2.24 & 4.48 & 7.98 & 17.89 & 160.17 \\
\hline \multirow[t]{9}{*}{ Female } & $16-20$ & Relative risk & 1.00 & 1.22 & 1.98 & 3.56 & 5.80 & 11.50 & 73.62 \\
\hline & & Lower & 1.00 & 1.10 & 1.40 & 1.88 & 2.39 & 3.35 & 8.41 \\
\hline & & Upper & 1.00 & 1.34 & 2.80 & 6.76 & 14.10 & 39.47 & 644.68 \\
\hline & $21-34$ & Relative risk & 1.00 & 0.18 & 2.04 & 3.76 & 6.25 & 12.74 & 88.13 \\
\hline & & Lower & 1.00 & 0.14 & 1.90 & 3.28 & 5.18 & 9.81 & 55.68 \\
\hline & & Upper & 1.00 & 0.22 & 2.19 & 4.30 & 7.54 & 16.54 & 139.51 \\
\hline & $35 t$ & Relative risk & 1.00 & 0.18 & 2.02 & 3.70 & 6.13 & 12.41 & 84.13 \\
\hline & & Lower & 1.00 & 0.14 & 1.83 & 3.06 & 4.71 & 8.61 & 44.19 \\
\hline & & Upper & 1.00 & 0.22 & 2.24 & 4.48 & 7.98 & 17.89 & 160.17 \\
\hline
\end{tabular}




\section{References}

Borkenstein, R.F., Crowther, R.F., Shumate. R.P., Ziel, W.B., and Zylman, R. (1974). The role of the drinking driver in traffic accidents. Blutalkohol 11 (Suppl. No. 1), 1-32.

Hingson, R., Heeren, Th., and Winter, M. (1996). Lowering state legal blood alcohol limits to 0.08\%: The effect on fatal motor vehicle crashes. AJPH, 86(9), 1297-1299.

Hosmer, D.W., and Lemeshow, S. (1989). Applied logistic regression. New York: Wiley \& Sons, Inc.

Hurst, P.M. (1973). Epidemiological aspects of alcohol in driver crashes and citations. Joumal of Safety Research, 5(3), 130-148.

Hurst, P.M. (1974). Epidemiological aspects of alcohol in driver crashes and citations. In Perrine, M.W. (Ed.), Alcohol, drugs, and driving. Abstracts and reviews (Technical report DOT HS 801 096). Washington, DC: National Highway Traffic Safety Administration.

Judkins, D. (1990). Fay's Method for variance estimation. Journal of Official Statistics, 6, 223-240.

Klein, T.M. (1986). A Method for estimating posterior BAC distributions for persons involved in fatal traffic accidents (DOT HS-807-094). Washington, DC: U.S. Department of Transportation.

Lestina, D.C., Greene, M., Voas, R.B., and Wells, J. (1999). Sampling procedures and survey methodologies for the 1996 survey with comparisons to earlier national roadside surveys. Evaluation Review, 23(1), 28-46.

Mayhew, D.R., Donelson, A.C., Beimess, D.J., and Simpson H.M. (1986). Youth, alcohol, and relative risk of crash involvement. Accid. Anal. and Prev., 52, 273-287.

Moskowitz, H., and Robinson, C. (1987). Driving-related skills impairment at low blood alcohol levels. In Noordzij, P.C., and Roszbach., T. (Eds.), Alcohol, drugs, and safety - T86. Amsterdam: Elsevier Sciences Publishers, B.V.

Nagelkerke, N.J.D. (1991). A note on the general definition of the coefficient of determination. Biometrika, 78, 691-692.

NASS/CDS Analytical user's manual 1988-1997. (1995). Washington, DC: U.S. Department of Transportation; National Highway Traffic Safety Administration; National Center for Statistics and Analysis, 67-68.

National Highway Traffic Safety Administration. (1995-96). Fatality Analysis Reporting System. Washington, DC: U.S. Department of Transportation.

Perrine, M.W., Peck, R.C., and Fell, J.C. (1989). Epidemiologic perspectives on drunk driving. In U.S.P.H.S. Office of the Surgeon General (Ed.). Surgeon General's workshop on drunk driving: Background papers (pp. 35-76). Washington, DC: U.S. Department of Health and Human Services.

Rubin, D.B. (1987). Multiple imputation of nonresponse in surveys. New York: Wiley \& Sons, Inc. 
Rubin, D.B., Schafer, J.L. and Subramanian, R. (1999). Multiple imputation of missing blood alcohol concentration (BAC) values in FARS (Report DOT-HS-808-816). Washington, DC: U.S. Department of Transportation, National Highway Traffic Safety Administration.

SAS Institute, Inc. (1996). SAS /STAT Software. Changes and enhancements: Release 6.11.

U.S. Department of Health and Human Services (HHS), NIH, NIAAA. (1993). Eighth Special Report to the U.S. on Alcohol and Health.

U.S. Department of Health and Human Services (HHS), NIH, NIAAA. (1997). Ninth Special Report to the U.S. on Alcohol and Health.

U.S. Department of Transportation. (1999). National Highway Traffic Safety Administration. Press Release No. 23-99. 1998 Traffic fatalities decline; Alcohol-related deaths reach record low.

U.S. Department of Transportation. (1998). Saving teenage lives: The Case for graduated driver licensing. National Highway Traffic Safety Administration (Technical report No. DOT HS 808 801).

Voas, R.B. and Tippetts, A.S. (April, 1999). The relationship of alcohol safety laws to drinking drivers in fatal crashes. National Highway Traffic Safety Administration Report.

Voas, R.B., Wells, J., Lestina, D., Williams, A., and Greene, M. (1997). Drinking and driving in the US: The 1996 National Roadside Survey. In Mercier-Guyon, C. (Ed.), Proceedings of the 14th International Conference on Alcohol, Drugs and Traffic Safety - T97, Annecy, 21 - 26 September 1997 (Vol. 3, pp. 1159-1166). Annecy, France: Centre d'études et de recherches en médecine du trafic.

WesVarPC Complex Samples Software: Version 3.0, User's guide. (1998). Chicago: SPSS Inc.

Wolfe, A.C. (1986). National Roadside Breathtesting Survey: Procedure and results. Washington, DC: Insurance Institute for Highway Safety.

Zador, P.L. (1991). Alcohol-related relative risk and fatal driver injuries in relation to driver age and sex. Journal of Studies on Alcohol, 52(4), 302-310. 
Acknowledgments. This research was funded by the National Highway Traffic Safety Administration under Purchase Order DTNH22-97-P-05174. The authors would like to express their thanks to JoAnn Wells and Chuck Farmer from the Insurance Institute for Highway Safety for assistance with the roadside survey data, and to Doug Duncan, consultant to Westat for data processing. 


\section{Appendix A}

\section{Weight adjustments to the exposure data}

Before receiving the survey exposure data, two adjustments were made for first and second stage selection refusals. The first involved the recalculation of sample selection probabilities for PSUs and police departments that refused to participate, or for which state laws about roadside checkpoints made it unlikely that they would participate. The second adjustment was made for one urban PSU where the survey site was only operated from 10:00 PM to midnight. Imputation was accomplished by estimating the number of drivers that would have passed the site and their BAC distribution using the early evening totals at this PSU and the traffic counts and BAC distribution of the other urban PSU in the geographic region. The sampling weights were adjusted using this calculation to account for the missing hours.

After the data were received, the full sample weight and the replicate weights were adjusted for nonresponse. Nonrespondents included the $\mathbf{4 8 5}$ observations that had missing values for one or more of the variables sex, age, or BAC level. Cross-classifications of the following variables were used to form the weighting classes required for the calculation of nonresponse adjustments: Region, Stratum, PSU, Police Jurisdiction, PRE_12PM (an indicator variable indicating whether or not the observation was taken before or after midnight), Site (indicating weekend day and time period of interview), and Sitenum (physical location within police jurisdiction). Adjustments were only considered acceptable if they were less than pre-determined upper bounds for both the full sample weight and the replicate weights, and if they were based on at least the predetermined minimum number of observations in each weighting class. Often the latter criterion was not met, and collapsing of cells was done to rectify this. Cells were collapsed, first within Site, then within PRE_12PM, then within Police Jurisdiction, and then within PSU, as necessary. 


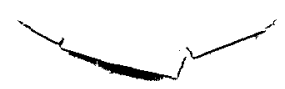

\section{Appendix B \\ Driver selection from FARS}

Drivers involved in a fatal crash during years 1995 or 1996 were selected using the NHTSA's Fatality Analysis Reporting System subject to the following criteria. The crash occurred in one of the 48 contiguous states in a county with a 1990 population of at least 20,000 , outside of special jurisdictions, on a paved road that was not classified as an interstate, other urban freeways or an expressway. Only passenger vehicle drivers 16 and over were included in the analyses.

We classified the selected drivers on injury and on the number of crash-involved vehicles into six (non-exclusive) driver groups obtained by crossing a two-way classification of driver survival (driver survived crash: yes or no) with a three-way classification of the number of crash-involved vehicles $(1,2$, any number). 


\section{Appendix C}

\section{Logistic regression models}

We classified driver involvement and driver exposure data on sex, age, and BAC level into $42=2 \times 3 \times 7$ levels each, determined the frequency distribution of involvement and weighted exposure, and calculated average BACs for crash involved drivers for every cell. We defined indicator variables for sex, age, selected BAC levels, and for certain of their interactions. We also calculated average BACs for driver groups by sex, age, and BAC level. We then used logistic regression to describe the relationship between involvement and exposure using these variables.

Our general model was of the following form:

$$
\operatorname{Logit}\left(p_{\text {sab }}\right)=\log \left(C_{\text {sab }} / E_{\text {sab }}\right)=\alpha+\beta^{\prime} x_{\text {sab }}+\text { residual, }
$$

where

$\operatorname{Logit}(p)=\log (p /(1-p))$ is the logistic transform of $p$, and

$\mathrm{C}_{\text {sab }}$ is the involvement frequency of drivers by sex (s), age (a), and BAC (b),

$E_{\text {sab }} \quad$ is the exposure weight of drivers by sex (s), age (a), and BAC (b),

$P_{s a b}$ is the proportion $C_{s a b} /\left(C_{s a b}+E_{s a b}\right)$ of involved drivers among exposed and involved drivers, by sex (s), age (a), and BAC (b),

$x_{\text {sab }}$ is a vector of explanatory variables for the $\mathrm{s}, \mathrm{a}, \mathrm{b}$ cell, and

$\alpha, \beta \quad$ are regression coefficients ( $\beta^{\prime}$ is the transpose of $\beta$ ).

We used the LOGISTIC procedure of the SAS system to estimate regression coefficients, their variances, and other model properties. Inverting equation $\mathrm{C}-1$ (and disregarding residuals), provides an expression for involvement odds in terms of model parameters:

$$
C_{\text {sab }} / E_{\text {sab }}=\exp \left(\alpha+\beta^{\prime} x_{\text {sab }}\right)
$$

One can compare the involvement odds between two cells with explanatory variables $x 2$ and $x 1$ :

$$
(\mathrm{C} 2 / \mathrm{E} 2) /(\mathrm{C} 1 / \mathrm{E} 1)=\exp \left(\beta^{\prime}(x 2-x 1)\right)
$$

If the two cells differ only in $\mathrm{BAC}$, and $\mathrm{b}$ is the corresponding regression coefficient, then the odds ratio, $\mathrm{OR}=(\mathrm{C} 2 / \mathrm{E} 2) /(\mathrm{Cl} / \mathrm{E} 1)=\exp (\mathrm{b}(\mathrm{BAC} 2-\mathrm{BAC} 1))$. Thus, the odds ratio depends exponentially on the regression coefficient of $\mathrm{BAC}$. Taking $\mathrm{BACl}=0$ for baseline, we see that driver $\mathrm{BAC}$ has an exponential effect on the involvement odds ratio relative to zero-BAC drivers, i.e., $O R(B A C)=\exp (b$ $B A C)$. We note that these odds ratio estimates are adjusted for all other covariates in the model. We note, also, that relative risk of crash involvement is well-approximated by the odds ratio provided that the number of crashes is small compared to total exposure.

In analogy to formula C-3, we estimated the lower and upper confidence bounds of a relative risk estimate by exponentiating the corresponding lower and upper confidence bounds of the corresponding regression coefficient. 


\section{Appendix D}

\section{Fay's method for generating replicate weights}

Balanced repeated replication (BRR) is generally used with multistage stratified sample designs. PSUs are first stratified and then two PSUs per stratum are selected using replacement sampling. Each replicate half sample estimate is formed by selecting one of the two PSUs from each stratum based on a Hadamard matrix and then using only the selected PSUs to estimate the parameter of interest. The weights for the units selected, in a standard BRR design, are multiplied by a factor of 2 to form the weights for the replicate estimate. For Fay's method however, the basic idea is to modify the sample weights less than in BRR, where half the sample is zero-weighted and the other half is double-weighted. Using Fay's method, one-half of the sample is weighted down by a factor $K$ and the remaining half is weighted up by a factor $2-\mathrm{K}$. The usual variance estimate formed by using the replicates is adjusted for the effects of the Fay factor by dividing by $(1-\mathrm{K})^{2}$. In this study, $\mathrm{K}$ was chosen as 0.50 as suggested in Judkins (1990). 


\section{Appendix E}

Estimating design-based variances in the presence of multiply imputed BACs

Rubin's method (1987) of estimating the total variance of a parameter estimate is constructed from repeated complete-data estimates for that parameter. Since we were interested in design-based variance estimates, we needed to generate these complete-data estimates using both full-sample $(k=0)$, and replicate weights $(k=1, \ldots, 12)$. Let, therefore, $Q_{\text {sab }}$ denote the estimate of parameter $Q$ based on the complete-data set that included the $m$-th BAC impute, and was calculated using the $k$-th weight (the value $k=0$ refers to the full-sample weight). We employed the following procedure to estimate total variance.

Step 1. Compute sampling variances for full-sample estimators $Q_{m 0}, m=1, \ldots, M=10$, of $Q$, using the formula:

$$
\mathrm{V}_{\mathrm{m}}=\mathrm{c} \sum_{\mathrm{k}=1}{ }^{\mathrm{G}}\left(\mathrm{Q}_{\mathrm{sab}}-\mathrm{Q}_{\mathrm{m} 0}\right)^{2}
$$

where

$$
\begin{array}{ll}
Q & \text { is any parameter of interest, } \\
Q_{m 0} & \text { is the m-th complete-data estimator of } Q \text { based on the full-sample weight, } \\
Q_{\text {sab }} & \text { is the m-th complete-data estimator of } Q \text { based on the } k \text {-th replicate weight, } \\
G & \text { is the number of replicate weights for the roadside survey, } G=12, \\
c & \text { is the constant we used for Fay's replication method, } 1 /\left[\left(12(1-\mathrm{K})^{2}\right], K=0.5,\right. \\
V_{m} & \text { is the design-based variance of full-sample estimator, } Q_{m 0}, \text { of parameter } Q \text {. }
\end{array}
$$

Step 2. Compute parameter Q's total variance across the 10 imputes as follows:

Average complete-data estimators based on the full-sample weight across the imputes:

$$
\mathrm{Q}_{\mathrm{M}}=\Sigma_{\mathrm{m}=1}^{\mathrm{M}} \mathrm{Q}_{\mathrm{m} 0} / \mathrm{M}
$$

Average the design-based variances of the full-sample estimators across the imputes:

$$
\mathrm{V}_{\mathrm{M}}=\Sigma_{\mathrm{m}=1}^{\mathrm{M}} \mathrm{V}_{\mathrm{m}} \mathrm{M}
$$

Compute the variance among the complete-data estimators:

$$
B_{M}=\Sigma_{m=1}^{M}\left(Q_{m 0}-Q_{M}\right)^{2} /(M-1)
$$

Compute the total variance of the quantity $\left(\mathrm{Q}-\mathrm{Q}_{\mathrm{M}}\right)$ from average design-based variance and between complete-data variance:

$$
\begin{aligned}
T_{M} & =V_{M}+(1+1 / M) B_{M} \\
& =\Sigma_{m=1}^{M} V_{m} / M+(1+1 / M) \Sigma_{m=1}^{M}\left(Q_{m 0}-Q_{M}\right)^{2} /(M-1)
\end{aligned}
$$

We used total variance for estimating lower and upper confidence bounds of relative risk, as discussed in Appendix C. 


\section{Appendix F}

\section{Alternative models logistic regression models for involvement/exposure ratios}

We used stepwise logistic regression to model involvement/exposure ratios in terms of optimally selected combinations of 18 main effects and interactions for age, age by sex, zero BAC, ${ }^{1}$ zero BAC by age, BAC under $0.02 \%,{ }^{2}$ and $\mathrm{BAC}$ under $0.02 \%$ by age. The model selected by stepwise regression for driver involvement in fatal two vehicle crashes brought all diagnostic statistics into the acceptable range. Specifically, the final model was judged adequate based on $\mathrm{p}=0.57$ (6 DF.) for the Hosmer-Lemeshow statistic of model fit. Unfortunately, this improvement was achieved by including two terms for sober drivers that showed sober drivers, especially sober drivers under age 35 , to be overrepresented relative to their expected involvement frequency based on models in which the effect of BAC on involvement is linear on the Logit scale. However, this model was not used for generating our estimates because it was not clear how it could be used to estimate relative risk with $\mathrm{BAC}=0$ as the baseline.

In the following exhibit, we display the regression coefficients of BAC by age in three models for involvement/exposure ratios. Two of these models, which did not include zero BAC terms, one for fatally injured drivers in single vehicle crashes and the other for driver involvement in two vehicle fatal crashes are also included in Table 4. The third model, which includes a zero BAC term is for driver involvement in two vehicle fatal crashes. Somewhat unsurprisingly, in every age group, the regression coefficients of BAC for driver involvement in fatal two vehicle crashes are substantially higher in the model that incorporates a zero BAC term, than in the corresponding model that does not. ${ }^{3}$ It is more surprising, however, that in every age group, the regression coefficients of BAC in the model for driver involvement in fatal two vehicle crashes that incorporates a zero BAC term is only slightly smaller than similar age-group regression coefficients for fatally injured drivers in single vehicle crashes. This suggests that positive BAC affects single vehicle fatalities and two vehicle crash involvement to roughly the same extent provided that not at-fault sober drivers are suitably accounted for. However, until confirmed by additional research, this finding must be considered more as a hypothesis than a definitive conclusion. Note, however, that similar suggestions were also made in Zador (1991).

\begin{tabular}{l|c|c|c}
\hline Age & $\begin{array}{l}\text { Driver involvement, } \\
\text { two vehicle fatal crashes, } \\
\text { zero BAC term included }\end{array}$ & $\begin{array}{l}\text { Fatally injured drivers, } \\
\text { single vehicle crashes }\end{array}$ & $\begin{array}{l}\text { Driver involvement, } \\
\text { two vehicle fatal crashes }\end{array}$ \\
\hline $16-20$ & 0.041 & 0.044 & 0.031 \\
$21-34$ & 0.024 & 0.029 & 0.019 \\
$35+$ & 0.024 & 0.027 & 0.018 \\
\hline
\end{tabular}

${ }^{\prime} \mathrm{BACO}=1$ if $\mathrm{BAC}=0, \mathrm{BAC} 0=0$ if $\mathrm{BAC}>0$.

${ }^{2} \mathrm{BACO2}=1$ if $\mathrm{BAC}<0.02, \mathrm{BACO2}=0$ if $\mathrm{BAC}>0.02$.

${ }^{3}$ This finding is, in fact, a mathematical consequence of the fact that zero BAC coefficients are always positive. 
DOT HS 809050

April 2000 